\title{
Glioblastoma Vasculature: From its Critical Role in Tumor Survival to Relevant in Vitro Modelling
}

\author{
Catarina Pacheco ${ }^{1,2,3}$, Cláudia Martins ${ }^{2,3}$, Joaquim Monteiro ${ }^{1}$, Fátima Baltazar ${ }^{4,5}$, \\ Bruno M. Costa ${ }^{4,5}$ and Bruno Sarmento ${ }^{1,2,3 *}$
}

${ }^{1}$ CESPU - Instituto de Investigação e Formação Avançada em Ciências e Tecnologias da Saúde, Gandra, Portugal, ${ }^{2}$ i3S - Instituto de Investigação e Inovação em Saúde, Universidade do Porto, Porto, Portugal, ${ }^{3}$ INEB - Instituto Nacional de Engenharia Biomédica, Universidade do Porto, Porto, Portugal, ${ }^{4}$ Life and Health Sciences Research Institute (ICVS), School of Medicine, University of Minho, Campus Gualtar, Braga, Portugal, 5ICVS/3B's - PT Government Associate Laboratory, Braga/Guimarães, Portugal

\section{OPEN ACCESS}

Edited by: Fabien Gosselet,

Université d'Artois, France

Reviewed by: Malgorzata Burek,

Julius Maximilian University of Würzburg, Germany

Caroline Mysiorek, Université d'Artois, France

*Correspondence: Bruno Sarmento bruno.sarmento@i3s.up.pt Specialty section This article was submitted to CNS Drug Delivery, a section of the journal Frontiers in Drug Delivery

Received: 27 November 2021 Accepted: 06 January 2022 Published: 17 February 2022

Citation:

Pacheco C, Martins C, Monteiro J, Baltazar F, Costa BM and Sarmento $B$ (2022) Glioblastoma Vasculature: From its Critical Role in Tumor Survival

to Relevant in Vitro Modelling.

Front. Drug. Deliv. 2:823412.

doi: $10.3389 /$ fddev.2022.823412
Biochemical and biophysical cues governing glioblastoma (GBM) progression are complex and dynamic. Tumor blood vessels, often recognized only by their transport functions, are more deeply involved in this process. Vessels are involved in tumor immune evasion, matrix alterations and stem cell stimulation, contributing for tumor treatment resistance and patients' poor survival. Given blood vessel complex and dynamic nature, they are hardly represented in conventional GBM monolayered in vitro models. However, other in vitro approaches, such as three-dimensional (3D) models, incorporating extracellular matrix (ECM), malignant and stromal cells, and promoting their communication, can resemble neovascularization, growing blood vessels in a tumor-like microenvironment. These models mimic GBM physiological architecture and key biochemical and biophysical environments, allowing the investigation of the impact of vascularization in tumor progression. For researchers in neuro-oncology field, 3D vascularized GBM models are of great interest. They are promising tools to evaluate individual driven neovascularization and identify mediators involved in those processes. Moreover, they may be used to test potential anti-GBM therapies targeting blood vessels or influenced by them. This review will discuss the significance of blood vessels in GBM and review novel 3D pre-clinical vascular models.

Keywords: 3D in vitro models, glioblastoma, microscale, neovascularization, perivascular niche, tissue engineering, tumor microenvironment

\section{INTRODUCTION}

Glioblastoma (GBM) is the most frequent, aggressive and lethal primary brain tumor in adults. According to the World Health Organization, it comprises isocitrate dehydrogenase (IDH) wild-type tumors presenting microvascular proliferation, or necrosis, or mutated telomerase reverse transcriptase (TERT) gene promoter, or amplified epidermal growth factor receptor (EGFR), or aberrant number of entire chromosome 7 or 10 (Louis et al., 2021). Although some studies tried to find a correlation between individuals age, gender or race and GBM higher incidence, this is still undefined, for what it seems to affect anyone (Shabihkhani et al., 2017; Bohn et al., 2018).

Standard treatment for newly diagnosed GBM cases includes maximal safe surgical resection followed by radiotherapy plus concomitant and adjuvant oral-administered temozolomide chemotherapy. However, despite many research and clinical efforts, GBM standard-of-care 
treatment is still associated with a dismal prognosis, with a median post-diagnosis survival time of less than 2 years (Tan et al., 2020).

The evolving understanding of cancer biology has evidenced the complex, dynamic and heterogeneous nature of the tumor microenvironment (TME). This is particularly the case in GBM, in which the TME comprises malignant cells with distinct proliferation, tumorigenicity and therapy resistance profiles, as well as various stromal cells, such as astrocytes, macrophages/ microglia, neurons, pericytes and endothelial cells (ECs). Moreover, these cells are embedded in a dynamically remodeled extracellular matrix (ECM) composed of non-cellular elements, like collagen, fibronectin and laminin (Behnan et al., 2019). An emerging body of evidence indicates that each one of these TME components is involved in GBM onset and progression, thus contributing to the poor prognosis of the disease.

High vascularization, or hypervascularization, is one of GBM main features. Rapid tumor growth leads to oxygen and nutrient increased requirements, which induces new blood vessel formation and, consequently, tumor high vascularization. Not only hypervascularization is directly involved in tumor cell feeding and survival, but it is also closely related to GBM invasiveness and progression. GBM invasion regulators are poorly understood but it is established GBM cells can take different routes to invade the brain, a major obstacle for complete surgical resection of the tumor (Montana and Sontheimer, 2011; Seano and Jain, 2020). These routes include the white matter tracts, the leptomeningeal space, the brain parenchyma and the vasculature, typically resulting in proximal and distant brain tumor recurrence (de Gooijer et al., 2018). Furthermore, several studies report the involvement of vasculature in a plurality of tumor-supporting signaling pathways, not simply related to a transport role. Tumor vasculature seems to communicate with other tumor components, as infiltrated immune system cells, glioblastoma stem cells (GSCs) and the ECM, therefore contributing to the assembly of the TME and driving tumor progression (Orr and Eberhart, 2015). In turn, these tumor components also promote vascularization, to favor malignancy (Das and Marsden, 2013). Hence, there is a current need to develop 1) novel and more effective therapies targeting the vascularization signaling pathways, and 2) a comprehensive representation of GBM biology in vitro, including tumor cells and representative TME components, to better assess the efficacy of these novel anti-GBM therapies before proceeding to in vivo models.

Regarding the representation of GBM biology in vitro, threedimensional (3D) in vitro models can incorporate various cell populations and ECM components, exhibiting a more physiologically relevant architecture compared with conventional two-dimensional (2D) in vitro models. Also, $3 \mathrm{D}$ models encourage cell-cell and cell-ECM interactions, without being as complex and expensive as animal models, respecting the 3Rs policy (Ferdowsian and Beck, 2011; Ruiz-Garcia et al., 2020). Thus, researchers have invested great efforts in the development of $3 \mathrm{D}$ in vitro models as sophisticated and biomimetic tools for fundamental biology studies and to assess the preliminary efficacy of newly proposed therapies.
Given that GBM hypervascularity has been associated with disease invasion, progression and therapy resistance, the incorporation of vasculature into $3 \mathrm{D}$ GBM in vitro models brings these systems closer to the native biology of the tumor, representing the complex crosstalk between tumor cells, tumorassociated blood vessels, and other non-neoplastic TME components in a more realistic manner. This opens avenues to study the behavior of the GBM perivascular niche in detail, understanding how vascular networks contribute to the aggressiveness and invasive profile of the tumor.

In 2015, Orr et al. summarized the different roles of tumorrelated blood vessels, including the conventional nutrient and oxygen delivery to tumor cells, but also less conventional roles, such as the maintenance of a stem cells' niche and the promotion of TME immunosuppression (Orr and Eberhart, 2015). More recently, in 2020 and 2021, Soubéran et al. and Gómez-Oliva et al., respectively, reviewed established GBM in vitro models and their usefulness to study tumor biology and to test new drugs (Gómez-Oliva et al., 2020; Soubéran and Tchoghandjian, 2020). Here, we will discuss the roles of blood vessels, specifically in GBM, how in vitro models have been used to represent the GBM vascularized tissue and their convenience to better understand neovascularization processes, find new therapeutic targets, study the tumor behavior in the perivascular niche, and test the potential of novel therapies in a biological-like environment.

We will briefly summarize the features of GBM vasculature, neovascularization processes and the contribution of vasculature to malignancy. In addition, we will address strategies of in vitro modelling of the GBM vascularized tissue. First, we will describe how the vasculature has been incorporated in spherical-, scaffold, 3D-bioprinting- and microfluidic-based models. Then, we will elucidate the significance of this modelling of the tumor's perivascular tissue in cancer biology studies and in therapy screening.

\section{GLIOBLASTOMA VASCULAR COMPARTMENT}

In general, human brain vasculature includes a layer of ECs, connected by cell-cell junctions, its basement membrane, shared with pericytes and astrocytes' endfeet, and microglia in the perivascular space - the known neurovascular unit (Arvanitis et al., 2020; Guyon et al., 2021). This unit integrates the bloodbrain barrier (BBB), a physiologic structure present in brain microvessels and capillaries, responsible for cerebral blood flow regulation (Kane, 2019). By establishing a highly selective, semi-permeable interface between the peripheral circulation and the central nervous system, BBB protects the latter from bloodborne xenobiotics and other potentially harmful molecules (Daneman and Prat, 2015).

Angiogenesis, firstly described in brain tumors in 1976, is the main process involved in GBM vascularization (Brem, 1976). As previously mentioned, the rapid tumor growth, and inherent need to circumvent the limited diffusion of oxygen and nutrients, activates tumor cells' expression and release of pro-angiogenic factors, such as the vascular-endothelial growth factor (VEGF) 
and basic fibroblast growth factor (bFGF). These molecules promote ECs' proliferation and migration signaling cascades, along with ECM remodeling, leading to the sprout of new blood vessels from pre-existing ones (Folkman, 1971). The angiogenic process has such a significant role in GBM survival and progression, which pushed the approval of anti-angiogenic strategies to its treatment, including bevacizumab (Avastin ${ }^{\circledR}$ ), a humanized monoclonal antibody, capable of binding VEGF and hinder angiogenesis (Cohen et al., 2009). Unfortunately, its clinical benefits are transient, followed by delayed tumor progression and patient death (de Groot et al., 2010; Gilbert et al., 2014).

In the last two decades, besides angiogenesis, four other mechanisms were identified as key in GBM vascularization: 1) vessel co-option, 2) vasculogenesis, 3) tumor cell transdifferentiation and 4) vascular mimicry [these mechanisms were reviewed elsewhere in detail (Hardee and Zagzag, 2012; Seano and Jain, 2020)]. Briefly, vessel co-option results from the ability of GBM cells to move towards and along blood vessels, attaching to their abluminal surface and replacing astrocytes and pericytes (Zhang et al., 2020). Through vessel cooption, the tumor ensures its own unlimited access to oxygen and nutrients, while facilitating invasion in the central nervous system by vascular routes (Griveau et al., 2018; Seano and Jain, 2020). Vasculogenesis involves the recruitment of circulating bone marrow derived cells, the EC progenitors, by the tumor. EC progenitors are then able to differentiate into ECs and assemble a primary vascular network in the TME (Lyden et al., 2001; De Palma et al., 2005). The transdifferentiation process, firstly reported in 2011 by Soda et al., is the differentiation of GSC tumor initiating cells overexpressing ETS variant 2 (ETV2), present in hypoxic tumor areas, into tumor-derived ECs that start to assemble tubular structures for blood flow (Soda et al., 2011; Zhao et al., 2018). And, lastly, tubular vasculogenic mimicry is the process by which GSCs differentiate into mural-like tumor cells, such as vascular smooth muscle cells or pericytes, to start to assemble vascular tubular structures for blood flow, independently of the presence of ECs (El Hallani et al., 2010; Scully et al., 2012).

Apart from vasculogenesis, all other mechanisms are independent on pro-angiogenic signals (Leenders et al., 2004; Yue and Chen, 2005; Soda et al., 2011). For instance, in viralvector mediated GBM mouse models, blocking VEGF, bFGF and the VEGF receptor (VEGF-R) increased the number of transdifferentiated ECs (Soda et al., 2011). In other words, VEGF, bFGF and VEGF-R blocking did not prevent neovascularization because, despite preventing angiogenesis, it was not able to disturb the transdifferentiation process.

Taking in consideration these mechanisms, it is clear that the GBM vascular compartment includes not only conventional neurovascular unit elements, but also tumor-derived ECs (TDECs) or mural-like tumor cells, as well as multiple molecular players controlling vascularization, as VEGF, bFGF or VEGF-R. This partly explains why neovascularization alternative mechanisms have been suggested as an explanation for tumor resistance to currently approved anti-angiogenic therapies (Kuczynski and Reynolds, 2020).
Independently of the underlying process, hypervascularity is correlated with a worse GBM prognosis and, even though tumor cells appear to control blood vessels to their benefit, it is described a multidirectional interplay between vasculature, tumor cells and other TME elements. As tumor cells and TME adjust and promote vascularization, the vascular compartment influences tumor cells' behavior and shapes the TME to foster disease progression. Thus, an accurate representation of the multiple TME elements is essential for fundamental biology studies, aiming to understand tumorigenesis driving pathways, and for the development and testing of novel and potentially effective GBM-targeted therapies. In addition, given the physiological function of blood vessels and that many approved and underdevelopment therapies are for intravenous administration, there is a driving force to shift from static to dynamic tumor vasculature representations in vitro. The latter may even be used as a tool for drug distribution studies in pre-clinical research.

\section{GLIOBLASTOMA VASCULATURE AND TUMOR MICROENVIRONMENT: MECHANISMS GOVERNING TUMOR INITIATION, GROWTH AND THERAPY RESPONSE}

Growing evidence about tumor-associated vasculature, in particular concerning astrocytes and ECs, indicates that these cells provide signaling cues to ensure tumor progression and survival. In fact, GBM activates astrocytes into reactive astrocytes, which, in turn, express and release high levels of cytokines, as interleukin 6 (IL-6) and connective tissue growth factor (CTGF), known to trigger the activation of oncogenic factors and to ease tumor invasion (Edwards et al., 2011). They also stimulate tumor cells' proliferation through stromal cell-derived factor 1 (SDF-1) and astrocyte elevated gene 1 (AEG-1). As a matter of fact, reactive astrocytes-derived signals are of such importance for tumor survival that AEG-1 inhibition is reported to induce programmed tumor cell death and reduce the tumor volume in animal models (Zou et al., 2016).

Endothelin is another major mediator in the crosstalk between vasculature and tumor cells. Both GBM-associated ECs and reactive astrocytes overexpress endothelin, whereas glioma cells express its receptors, endothelin receptor A (ETA) and endothelin receptor B (ETB). Through binding to ETA or ETB, endothelin activates the AKT and MAPK signaling pathways in tumor cells, promoting chemotherapy resistance (Kim et al., 2015). Also, interestingly, astrocytes produce and secrete L-glutamine, addressing key tumor metabolic needs (Guan et al., 2018). Therefore, in general, blood vessel cells actively participate in the tumorigenesis process.

On the other hand, recent experimental studies report that vasculature can be intimately involved in environmental changes to create an ideal TME. In the following Sections 3.1-3.3, the communication between GBM blood vessels and GSCs, immune 
system cells and ECM will be described in detail, as well as its consequences in tumor progression.

\subsection{Glioblastoma Vasculature Shelters and Regulates Glioblastoma Stem Cells}

GSCs are among the multiple malignant cellular subpopulations of GBM. GSCs share some characteristics with neural stem cells, like being able to self-renewal, express stemness markers (e.g., Nestin or Olig2) and undergo multilineage differentiation. They are known to be intrinsically resistant to radiotherapy and chemotherapy, contributing to intratumor heterogeneity, invasion and recurrence after treatment (Liu et al., 2006; Shi et al., 2018; Mazor et al., 2019; Bhaduri et al., 2020).

The intimate relationships between tumor vasculature and GSCs have been recognized and studied for more than a decade. In 2007, Calabrese et al. reported the presence of GSCs around tumor capillaries in patient samples, which focused the attention of researchers in the connection between GSCs and blood vessels (Calabrese et al., 2007). Since then, several studies found that the narrow interaction between vasculature and GSCs is essential to support GSCs' tumor propagating ability. Moreover, GSCs themselves stimulate blood vessel development, which justify their residence mostly in perivascular niches (Brooks and Parrinello, 2017).

Tumor blood vessels and GSCs crosstalk can be established by direct cell-to-cell contact or the release of soluble factors. For example, tumor vasculature ECs assist GSCs self-renewal and maintenance through the expression of Notch ligands, specifically the jagged canonical Notch ligand 1 (JAG1) and delta like canonical Notch ligand 4 (DLL4), which interact with the GSCs Notch receptor (Zhu et al., 2011). In fact, the knockdown of tumor-associated JAG1 and DLL4 in ECs compromises GSCs-derived tumor development, which proves the relevance of Notch signaling in the tumorigenic capacity of GSCs (Zhu et al., 2011). Nitric oxide (NO) is another important regulator in this crosstalk (Charles et al., 2010). It is known that GBM-associated ECs express high levels of endothelial NO synthase (eNOS). NO released from the endothelial layer was shown to diffuse into adjacent GSCs, thus regulating the ability of these cells to form the tumor tissue in vitro and in vivo (Charles et al., 2010). Similarly, ECs-derived interleukin 8 (IL-8) has also been suggested as a mediator of GSCs proliferation and migration (Infanger et al., 2013). The Sonic hedgehog (Shh) protein is heavily produced and released from neovascular ECs and reactive astrocytes. Through binding to its receptor on GSCs surface, Shh activates the hedgehog pathway, known to maintain stem cells self-renewal (Becher et al., 2008; Yan et al., 2014). Over the years, evidence has also shown the involvement of fibroblast growth factor (FGF) in GSCs maintenance, supported by ECs. GBM cells in the presence of FGF can acquire a GSC phenotype, evidencing the contribution of tumor ECs in the maintenance of GSC pools (Fessler et al., 2015).

In turn, GSCs also contribute to the maintenance and expansion of the vascular compartment. GSCs can differentiate into tumor-derived ECs or mural-like ECs, increasing tumor vascularization (Soda et al., 2011; Scully et al., 2012). Moreover,

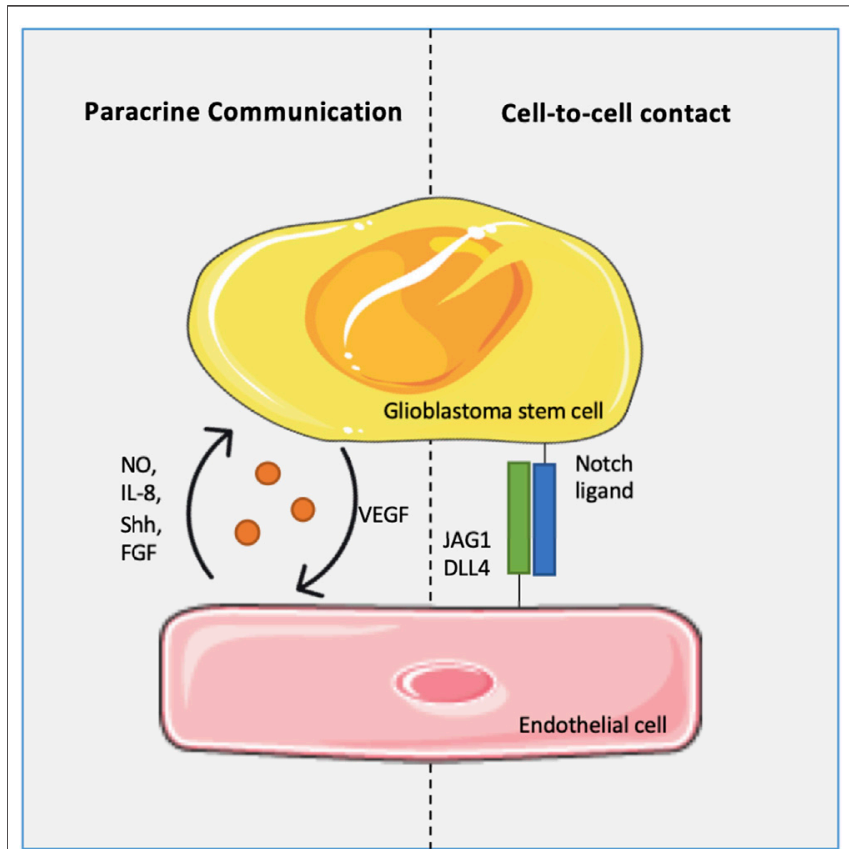

FIGURE 1 | Glioblastoma stem cells (GSCs) and endothelial cells (ECS) communication. The communication is bidirectional and occurs either by direct cells contact or by paracrine signaling. ECs play a critical role in the survival and self-renewal of GSCs via jagged canonical Notch ligand 1 (JAG1), delta like canonical Notch ligand 4 (DLL4), nitric oxide (NO), interleukin 8 (IL-8), sonic hedgehog protein (Shh) and fibroblast growth factor pathway (FGF), among others. In turn, GSCs release vascular endothelial growth factor (VEGF) promoting ECs proliferation.

GSCs sustain continuous angiogenesis by VEGF secretion (Bao et al., 2006). Therefore, it seems to be established a self-sustained positive feedback mechanism between GSCs and tumor-associated ECs - GSCs induce EC proliferation and survival, while the latter expands the perivascular niche, where GSCs reside, and ensure their maintenance (Figure 1).

GSCs are also present in hypoxic niches, far from perivascular niches. In the tumor bulk, hypoxia regulates stemness through hypoxia inducible factor 1-alpha (HIF-1 $\alpha$ ) and 2-alpha (HIF-2 $\alpha$ ) stabilization, an upstream transcription factor of self-renewal, dedifferentiation and pro-angiogenic genes (Li et al., 2009; Qiang et al., 2012). The knockdown of HIF-1 $\alpha$ or HIF-2 $\alpha$ in GSCs results in the loss of stem cell-like characteristics, affecting the expression and secretion of VEGF (Li et al., 2009; Méndez et al., 2010). Overall, this strongly supports the role of GSCs, both from perivascular and hypoxic niches, in tumor neovascularization.

\subsection{Glioblastoma Vasculature Promotes Tumor Immunosuppressive Environment}

As previously described, the GBM microenvironment harbors both malignant and non-malignant cells, including immune system cells. Various immune cell types can be found in different tumors, as regulatory $\mathrm{T}$ cells (Treg) or myeloidderived suppressor cells (MDSCs) but, particularly in GBM case, microglia/macrophages are the most frequently present, 


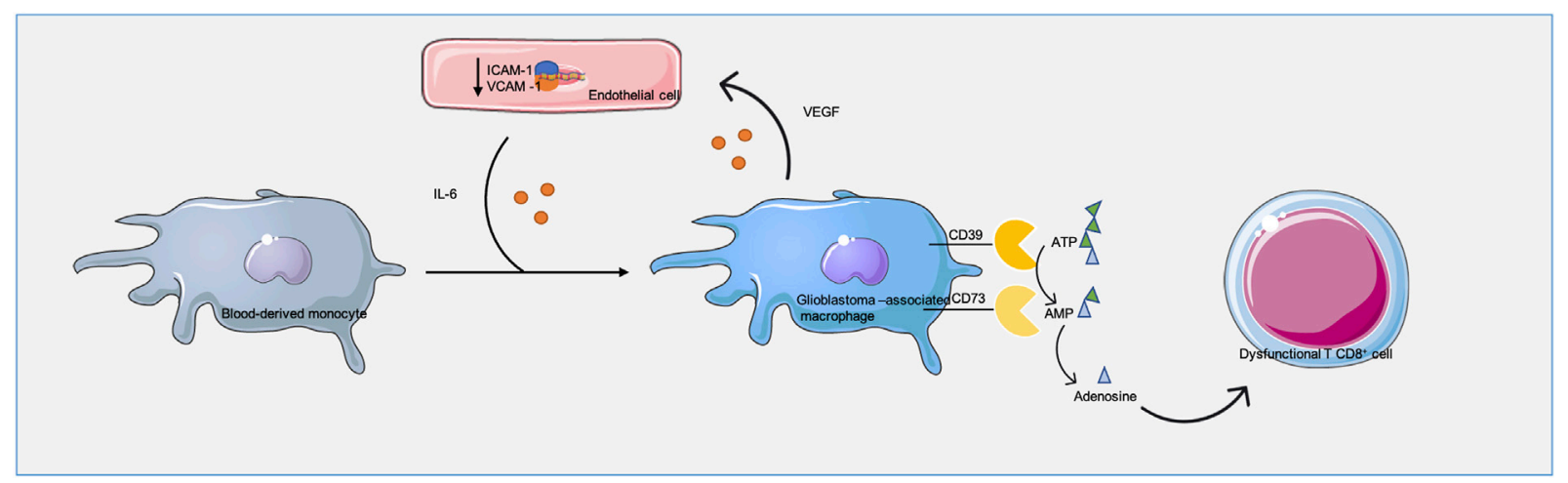

FIGURE 2 | Glioblastoma-associated macrophages (GAMs) and endothelial cells (ECs) communication. This communication regulates both macrophage infiltration/polarization in the tumor and ECs behavior. Through interleukin 6 (IL-6), ECs assist macrophages pro-tumoral phenotype while macrophages vascular endothelial growth factor A (VEGFA), metalloproteinase 9 (MMP9), urokinase-type plasminogen activator (UTPA) and thymidine phosphorylase (TP) drive ECs proliferation, expansion and lower ECs intracellular adhesion molecule 1 (ICAM) and vascular adhesion molecule 1 (VCAM) levels, lowering their function as entry points for immune cells into the tumor. In addition, GAMs ectonucleotidase 39 (CD39) and 73 (CD73) convert adenosine triphosphate (ATP) and adenosine monophosphate (AMP) into adenosine, which leads to T cell dysfunction.

representing about $30-40 \%$ of all tumor cell content (Vega et al., 2008; Shang et al., 2015; Zhang et al., 2016).

In the tumor site, macrophages can undergo different activation processes, acquiring a wide spectrum of phenotypes, depending on the surrounding environment (Fu et al., 2020). This activation is highly complex and dynamic, and evidence indicates that GBM-associated macrophages (GAMs) maintain a chronic inflammation in an initial phase, through the release of tumor necrosis factor alpha (TNFa), IL-6 and interferon gamma (INF$\gamma$ ), creating a mutagenic environment favorable to tumor progression (Cassetta and Pollard, 2018). Then, GAMs preferentially differentiate into an anti-inflammatory phenotype (Mantovani et al., 2002). Anti-inflammatory or M2 macrophages also support tumor survival by suppressing antitumor immunity, namely cytotoxic $\mathrm{T}$ cells inflammatory responses (Hambardzumyan et al., 2016).

Tumor cells and tumor vasculature closely regulate GAMs, from their recruitment to their differentiation, maintenance and immunosuppressive role. Apparently, glioma cells initiate this process. They are major sources of SDF-1, glial cell derived neurotrophic factor (GDNF) and colony stimulating factor 1 (CSF-1), stimulating monocyte diapedesis and differentiation into M2 macrophages (Wang et al., 2012; Ku et al., 2013; Pyonteck et al., 2013; Sielska et al., 2013). In addition, endothelial cells release high levels of IL-6, which induces macrophage pro-tumoral phenotype, via HIF-2 $\alpha$ activation (Wang et al., 2018). Therefore, GAMs concentrate mainly in tumors' perivascular and perinecrotic niches (Zeiner et al., 2019).

Once in the TME, GAMs display a pro-angiogenic profile (Tamura et al., 2019). In fact, the most important angiogenesis inducer - VEGFA - is highly expressed by these cells. Also, GAMs' enzymes, including matrix metalloproteinase 9 (MMP-9) and urokinase-type plasminogen activator (uTPA), drive ECM degradation, whereas other GAMs' enzymes, such as thymidine phosphorylase (TP), drive pericyte and EC migration (Hotchkiss et al., 2003; Piao et al., 2005; Du et al., 2008; Riabov et al., 2014;
Zhu et al., 2017). Therefore, macrophage recruitment and differentiation contribute to neovascularization and, consequently, for tumor growth and invasion. Overall, this suggests that tumor-associated ECs and GAMs support each other in the TME, and both support tumor growth (Figure 2).

As previously mentioned, GAMs impair cytotoxic T cell antitumor responses. GAMs present high levels of ectonucleotidase CD39, which cooperates with CD73 generating adenosine and, consequently, driving $\mathrm{T}$ cell immunity suppression (Takenaka et al., 2019). However, GBM is known as a "cold tumor," meaning it presents low levels of $\mathrm{T}$ cells. This might happen because GAMs prevent $T$ cell transmigration and tumor infiltration by interacting with ECs - pro-angiogenic factors derived from GAMs lower the expression of adhesion molecules on the surface of ECs. This mechanism, known as endothelial anergy, reduces the intercellular levels of adhesion molecule 1 (ICAM-1) and vascular adhesion molecule 1 (VCAM-1), essential for $\mathrm{T}$ cell transmigration and tumor accumulation, thus protecting the tumor from any potential immune attack (Wang et al., 2021) (Figure 2).

\subsection{Glioblastoma Vasculature Supports Extracellular Matrix Remodeling, Contributing to Tumor Onset, Progression and Continuous Angiogenesis}

For a long time, ECM was seen as a purely structural tumor component. However, since the 1990s, evidence began to emerge that ECM is closely involved in cellular migration, differentiation, survival and invasion, contributing to tumor development and expansion (Bilozur and Hay, 1988; Koochekpour et al., 1995; Bouterfa et al., 1997). Healthy brain ECM has an absolutely unique composition, with relatively small amounts of proteins, as collagen or fibronectin, and greater content of glycosaminoglycans, such as hyaluronic acid, which may or may not be bound to proteins, forming proteoglycans (Novak 
and Kaye, 2000). This nature provides brain an amorphous soft structure, termed as perineural net (Mouw et al., 2014).

In contrast to what happens in healthy brain, brain tumors trigger profound alterations in the amount and deposition of ECM, its composition (particularly upregulation of collagen, fibrin and laminins), organization and post-translation modifications, which lead to the development of a less amorphous, denser and more rigid structure, necessary for disease establishment and progression (Belousov et al., 2019).

Both GBM malignant and stromal cells are important for the above-described ECM remodeling. Through an increased production of hyaluronic acid, laminin, collagen IV and VI or fibronectin, these cells create a more compact and denser ECM (Delpech et al., 1993; Bouterfa et al., 1999; Kawataki et al., 2007; Mammoto et al., 2013; Henke et al., 2019). In addition, these cells upregulate receptors and enzymes responsible for cell-matrix connections, which together with the tumor remodeled ECM, seems to facilitate tumor invasion, migration, angiogenesis and overall growth (Henke et al., 2019).

For instance, both tumor and tumor-related ECs are known to produce laminin $\alpha 2$ to a large extent (Kawataki et al., 2007). On its own, an increase in ECM laminin content, and consequently, in tumor matrix density, hampers drug diffusion and radiation penetration, protecting tumor against multiple treatments (Henke et al., 2019). In addition, direct contact between extracellular laminin and its integrin receptors, on GBM cells and GSC surface, is involved in tumor cell migration and radiotherapy resistance, respectively (Lathia et al., 2012; EllertMiklaszewska et al., 2020). Therefore, tumor-associated blood vessels enable tumor proliferation and resistance through their contribution to ECM abundance and stiffness.

According to previous studies, GBM core and margin stiffness is about ten times greater than normal brain tissue stiffness (1: $0.1 \mathrm{kPa}$ ) (Miroshnikova et al., 2016). Besides creating a physical barrier, some studies reveal that ECM hardness dictates GBM cell behavior and angiogenesis. In response to stronger ECM forces, through mechanosensing and mechanotransduction processes, GBM cells change their size, shape, signaling pathways and density. For instance, in vitro studies showed that tumor cell compactness induces the production of collagen IV and VI, and the expression of lysyl oxidase, supporting an even greater ECM stiffness. This compactness, in turn, incites the expression of proangiogenic factors, leading to tumor vascularization (Mammoto et al., 2013).

As mentioned before, angiogenesis is a two-step process involving EC activation followed by endothelial cell sprouting, when ECs proliferate and migrate to assemble new blood vessels. During migration, ECs recognize and specifically bind to ECM ligands through integrin receptors, generating the necessary traction and cytoskeleton reorganization for this movement (Wang et al., 2005). Also, EC movement requires prior degradation of the vascular basal membrane and ECM remodeling through metallo, serine and cysteine proteases. uTPA, activator of proteolytic enzyme urokinase-type plasminogen (uTP), MMP9 and cathepsin B are highly expressed in GBM (Forsyth et al., 1999; Konduri et al., 2001; Rustamzadeh et al., 2003). ECM breakdown promoted by these proteases results in release of VEGF, FGF and epidermal growth factor (EGF), previously bound to ECM, and of matrix components that become free to interact with GBM cell integrins and activate $\mathrm{MEK}$ and $\mathrm{PI} 3 \mathrm{~K}$ signaling pathways, inducing the synthesis and/or activation of pro-angiogenic molecules (Lakka et al., 2005). Thus, tumor-induced ECM remodeling works as an angiogenesis activator signal, either by allowing EC sprouting, or by contributing to EC proliferation.

All these observations imply an obvious and close relationship between GBM blood vessels, ECM and tumor aggressiveness. Blood vessels contribute to the formation of regions of remodeled ECM, therefore promoting tumor proliferation, migration and invasion; on the other hand, the remodeled ECM supports continuous angiogenesis (Figure 3).

\section{TISSUE ENGINEERING STRATEGIES TO MODEL GLIOBLASTOMA VASCULARIZED TISSUE IN VITRO}

Over the past years, multiple in vitro and in vivo systems have been used to study GBM and to test the efficacy of novel treatments. Among these in vitro systems, monolayer or $2 \mathrm{D}$ cell cultures are classical and well-established approaches, routinely used for the maintenance and growth of animal or human immortalized cell lines and patient-derived cells. Immortalized cell lines are easily manipulated in vitro and quickly reach high cellular densities under culture conditions, allowing the screening of anti-tumor drugs with faster and more reproducible outcomes (Gómez-Oliva et al., 2020). On the other hand, patient-derived primary cultures take longer time to grow, but they preserve better the tumor genomic profile and heterogeneity, allowing the investigation of personalized therapies (Sottoriva et al., 2013; Jacob et al., 2020). For these reasons, the use of $2 \mathrm{D}$ cell cultures in the fields of biomedical and pharmaceutical research has been preferentially chosen (Ledur et al., 2017). Nevertheless, there are several caveats regarding these systems, such as successive cell passages that lead to phenotypic changes and selection of cells with greater proliferative abilities, and poor correlation with in vivo cell-cell/cell-ECM interactions and tumor heterogeneity. Therefore, even if these models are used as the first tool for preclinical screening, it would be advantageous to combine them with more powerful and biologically relevant models (Allen et al., 2016; Gómez-Oliva et al., 2020).

Regarding in vivo models, xenograft, genetically engineered and viral-vector mediated transduction models, are the most frequently used GBM pre-clinical models (Miyai et al., 2017; Hubbard et al., 2018). However, although these systems generate complex tumors, enabling the screening of drugs in an individual basis and study of the mechanisms of GBM drug resistance, they are still far from flawless. Interspecies differences and the lack of competent immune system limit their predictive value, while cost, time consumption and ethical issues limit their applicability (Rangarajan and Weinberg, 2003; Reduce Refine Replace, 2010).

Thus, there is a current effort to develop $3 \mathrm{D}$ sophisticated in vitro systems able to overcome the aforementioned limitations of in vivo models and become good complementary models for GBM 


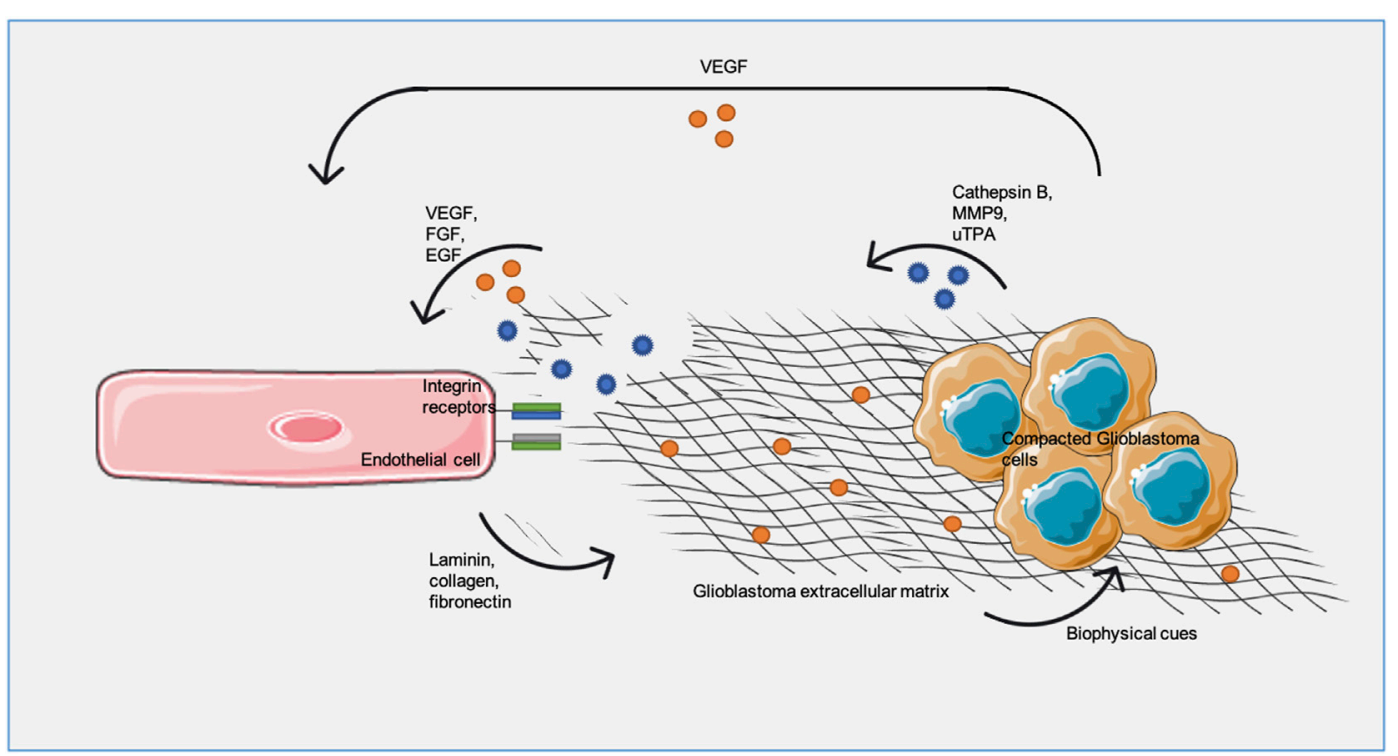

FIGURE 3| - Glioblastoma extracellular matrix (ECM) and endothelial cells (ECs) communication drives matrix remodeling and angiogenesis. ECs produce laminin, collagen and fibronectin increasing ECM density and, consequently, pro-angiogenic factors, such as vascular endothelial growth factor (VEGF), production/release from tumor cells. Additionally, tumor-derived ECM breaking though cathepsin B, metalloproteinase (MMP9) and urokinase-type plasminogen activator (UTPA) releases anchored pro-angiogenic factors, as VEGF, fibroblast growth factor pathway (FGF) and epidermal growth factor (EGF), promoting vascular proliferation.

research. Attempts to engineer and improve in vitro models drove the development of platforms that incorporate specific biochemical and biophysical TME signals and recapitulate the communication between tumor cells, surrounding vasculature, stromal cells and ECM components. In fact, for instance, it has been shown that angiogenesis occurring in 2D systems is significantly different from angiogenesis in 3D (Cui et al., 2018). Since it is now widely accepted that GBM progression, aggressiveness and invasion is highly dependent on neovascularization, 3D models recapitulating the vascularized tumor are expected to be valuable tools in therapeutic targets research and drug screening.

Up next, the progress of vascularized GBM in vitro models will be outlined. A brief description of each in vitro model along with their principal achievements is presented in Table $\mathbf{1}$.

\subsection{Spherical Models - "Free" or Matrix-Supported Spheroids}

Spheroids are a group of cells that grow together in a spherical, non-adherent structure. Their multi-dimensional structure creates better conditions than classic $2 \mathrm{D}$ models to replicate physiologic-like cell-cell and cell-matrix interactions, $\mathrm{pH}$ gradients, oxygen availability and dynamic metabolic demands of tumors, representing the multiple in vivo tumor regions, from the senescent core to the proliferative periphery. Furthermore, several studies comparing tumor cell behavior in $2 \mathrm{D}$ and $3 \mathrm{D}$ systems revealed that spheroids better recapitulate the tumor genetic expression and chemotherapy resistance, often observed in vivo (Lin and Chang, 2008). From a technical point of view, they are inexpensive, easy to maintain and to manipulate (Lu and Stenzel, 2018). Thus, spheroid models have been extensively investigated and used to mimic human tumors, including GBM.
In the literature, the most frequently reported GBM spheroids comprise only one human or one mouse cell line and are used to test the tumor penetration ability and cytotoxic activity of novel therapies, including cutting-edge nanosystem-based therapies. For instance, in a recent work, Broekgaarden et al. used human derived U87MG spheroids and mouse derived F98 spheroids to test the tumor penetration and radiotherapy effectiveness of surfacefunctionalized gold nanoparticles (Broekgaarden et al., 2020). While these models are advantageous when compared with monolayered cell cultures, they still lack relevant TME elements, and do not mimic perivascular regions.

To overcome these weaknesses, other approaches are based on spheroids assembled with both tumor and endothelial cells, subsequently incorporated into hydrogels or biofilms made of Matrigel or human derived ECM components, as collagen, hyaluronic acid or fibrin. These systems allow better replication of the natural tumor tissue organization (Pan et al., 2019). Hydrogels generate a native tumor-like environment, allowing EC sprouting and tumor cell invasion, critical for brain tumor angiogenesis research (Rustad et al., 2012). In line with this, spheroids of GBM primary cells and EC embedded in ECM gels were recently reported (Table 1) (McCoy et al., 2019; Tatla et al., 2021b). In these models both EC and GBM cell migration was observed, which confirms models are appropriate for angiogenesis and GCS transdifferentiation study (McCoy et al., 2019; Tatla et al., 2021b). Through biochemical analysis of their spheroid model, McCoy et al. found that endothelial cells stimulate GBM cell migration, via IL-8 secretion. Furthermore, the model developed by McCoy et al. was useful to test potential GCS transdifferentiation inhibitors (McCoy et al., 2019).

Despite the benefits of these spherical models, they are limited by lack of the blood flow shear stress, which Plays an important role in in vivo neovascularization 
TABLE 1 | - 3D vascularized glioblastoma in vitro models.

\begin{tabular}{|c|c|c|c|c|c|c|c|c|c|}
\hline Model type & Tumor cells & Stromal cells & $\begin{array}{l}\text { Matrix-like } \\
\text { material }\end{array}$ & $\begin{array}{l}\text { Perfusion } \\
\text { capacity }\end{array}$ & $\begin{array}{l}\text { Accurate BBB } \\
\text { representation? }\end{array}$ & Main achievements & Described applications & Main limitations & References \\
\hline \multirow[t]{2}{*}{$\begin{array}{l}\text { Spherical } \\
\text { models }\end{array}$} & $\begin{array}{l}\text { Human glioblastoma } \\
\text { cell line (NCH82) and } \\
\text { patient-derived } \\
\text { glioblastoma cells }\end{array}$ & $\begin{array}{l}\text { HUVECs and human } \\
\text { dermal fibroblasts }\end{array}$ & Fibrinogen & No & $\begin{array}{l}\text { No, lacks pericytes, } \\
\text { astrocytes, and } \\
\text { microglia cells }\end{array}$ & $\begin{array}{l}\text { Recapitulates tumor- } \\
\text { associated } \\
\text { vascularization }\end{array}$ & $\begin{array}{l}\text {-Study of tumor } \\
\text { vascularization } \\
\text { mechanisms }\end{array}$ & $\begin{array}{l}\text {-Lack of mechanical } \\
\text { stimuli, as blood flow } \\
\text { shear stress }\end{array}$ & $\begin{array}{l}\text { Tatla et al. } \\
\text { (2021a) }\end{array}$ \\
\hline & $\begin{array}{l}\text { Patient-derived } \\
\text { glioblastoma cells }\end{array}$ & $\begin{array}{l}\text { Immortalized human } \\
\text { cerebral } \\
\text { microvascular ECs }\end{array}$ & Collagen & No & $\begin{array}{l}\text { No, lacks pericytes, } \\
\text { astrocytes, and } \\
\text { microglia cells }\end{array}$ & $\begin{array}{l}\text { Recapitulates } \\
\text { vascular-induced } \\
\text { GCSs invasion }\end{array}$ & $\begin{array}{l}\text {-Screening of tumor } \\
\text { vascularization inhibitors }\end{array}$ & & $\begin{array}{l}\text { McCoy et al. } \\
\text { (2019) }\end{array}$ \\
\hline \multirow[t]{4}{*}{$\begin{array}{l}\text { 3D-brioprinted } \\
\text { models }\end{array}$} & $\begin{array}{l}\text { Patient-derived } \\
\text { glioblastoma cells }\end{array}$ & HUVECS & $\begin{array}{l}\text { Glycidyl } \\
\text { methacrylate, } \\
\text { hyaluronic acid } \\
\text { and gelatin } \\
\text { methacrylate }\end{array}$ & No & $\begin{array}{l}\text { No, lacks pericytes, } \\
\text { astrocytes, and } \\
\text { microglia cells }\end{array}$ & $\begin{array}{l}\text { Recapitulates tumor } \\
\text { biophysical properties } \\
\text { and its impact on } \\
\text { tumor-associated } \\
\text { vascularization }\end{array}$ & $\begin{array}{l}\text {-Study of ECM impact on } \\
\text { tumor vascularization } \\
\text { mechanisms }\end{array}$ & $\begin{array}{l}\text {-Model developed } \\
\text { limited by the access } \\
\text { to 3D bioprinters } \\
\text { and their inks }\end{array}$ & $\begin{array}{l}\text { Tang et al. } \\
\text { (2021) }\end{array}$ \\
\hline & $\begin{array}{l}\text { Human glioblastoma } \\
\text { cell line (U87) }\end{array}$ & $\begin{array}{l}\text { HUVECs and normal } \\
\text { human lung } \\
\text { fibroblasts }\end{array}$ & $\begin{array}{l}\text { Gelatin, alginate } \\
\text { and fibrinogen }\end{array}$ & No & $\begin{array}{l}\text { No, lacks pericytes, } \\
\text { astrocytes, and } \\
\text { microglia cells }\end{array}$ & $\begin{array}{l}\text { Recapitulates tumor- } \\
\text { associated } \\
\text { vascularization and its } \\
\text { impact on tumor cells }\end{array}$ & $\begin{array}{l}\text {-Study of tumor } \\
\text { vascularization } \\
\text { mechanisms } \\
\text {-Screening of tumor } \\
\text { inhibitors }\end{array}$ & $\begin{array}{l}\text {-Downscaling is } \\
\text { hindered by } \\
\text { currently available } \\
\text { equipment's } \\
\text { resolution }\end{array}$ & $\begin{array}{l}\text { Han et al. } \\
(2020)\end{array}$ \\
\hline & $\begin{array}{l}\text { Patient-derived } \\
\text { glioblastoma cells }\end{array}$ & HUVECS & Collagen & Yes & $\begin{array}{l}\text { No, lacks pericytes, } \\
\text { astrocytes, and } \\
\text { microglia cells }\end{array}$ & $\begin{array}{l}\text { Recapitulates } \\
\text { vascular-induced } \\
\text { tumor invasion }\end{array}$ & $\begin{array}{l}\text {-Study of tumor invasion } \\
\text { and therapeutic resistance } \\
\text { mechanisms in the } \\
\text { perivascular space }\end{array}$ & & $\begin{array}{l}\text { Ozturk et al. } \\
\text { (2020) }\end{array}$ \\
\hline & $\begin{array}{l}\text { Human glioblastoma } \\
\text { cell line (U87) }\end{array}$ & HUVECS & $\begin{array}{l}\text { Pig brain } \\
\text { decellularized } \\
\text { ECM and silicone }\end{array}$ & No & $\begin{array}{l}\text { No, lacks pericytes, } \\
\text { astrocytes, and } \\
\text { microglia cells }\end{array}$ & $\begin{array}{l}\text { Recapitulates tumor } \\
\text { biophysical properties }\end{array}$ & $\begin{array}{l}\text {-Study of tumor invasion } \\
\text { and therapeutic resistance } \\
\text { mechanisms in the } \\
\text { perivascular space }\end{array}$ & & $\begin{array}{l}\text { Yi et al. } \\
\text { (2019) }\end{array}$ \\
\hline \multirow[t]{5}{*}{$\begin{array}{l}\text { Glioblastoma- } \\
\text { on-a-chip }\end{array}$} & $\begin{array}{l}\text { Human glioblastoma } \\
\text { cell line (U87) }\end{array}$ & $\begin{array}{l}\text { HUVECs, normal } \\
\text { human lung } \\
\text { fibroblasts and } \\
\text { human placenta } \\
\text { pericytes }\end{array}$ & $\begin{array}{l}\text { Fibrinogen and } \\
\text { collagen }\end{array}$ & Yes & $\begin{array}{l}\text { No, lacks astrocytes, } \\
\text { and microglia cells }\end{array}$ & $\begin{array}{l}\text { Recapitulates tumor- } \\
\text { associated } \\
\text { vascularization }\end{array}$ & $\begin{array}{l}\text {-Study of tumor } \\
\text { vascularization } \\
\text { mechanisms }\end{array}$ & $\begin{array}{l}\text {-Limited control over } \\
\text { models' size and } \\
\text { cells distribution }\end{array}$ & $\begin{array}{l}\text { Kim et al. } \\
\text { (2013) }\end{array}$ \\
\hline & $\begin{array}{l}\text { Human glioblastoma } \\
\text { cell lines (U87, U251, } \\
\text { U373, LN229, T98G) } \\
\text { or patient-derived } \\
\text { glioblastoma cells }\end{array}$ & $\begin{array}{l}\text { HUVECs, normal } \\
\text { human lung } \\
\text { fibroblasts }\end{array}$ & $\begin{array}{l}\text { Fibrinogen and } \\
\text { collagen }\end{array}$ & Yes & $\begin{array}{l}\text { No, lacks pericytes, } \\
\text { astrocytes, and } \\
\text { microglia cells }\end{array}$ & $\begin{array}{l}\text { Recapitulates tumor- } \\
\text { associated } \\
\text { vascularization }\end{array}$ & $\begin{array}{l}\text {-Study of tumor } \\
\text { vascularization } \\
\text { mechanisms } \\
\text { - Screening of tumor } \\
\text { vascularization inhibitors }\end{array}$ & $\begin{array}{l}\text { - Model developed } \\
\text { limited by the access } \\
\text { to pumps, valves } \\
\text { and other pieces of } \\
\text { equipment }\end{array}$ & $\begin{array}{l}\text { Amemiya } \\
\text { et al. (2021) }\end{array}$ \\
\hline & $\begin{array}{l}\text { Adult mice neural stem } \\
\text { cells overexpressing } \\
\text { H-Ras(V12) }\end{array}$ & HUVECS & Collagen & No & $\begin{array}{l}\text { No, lacks pericytes, } \\
\text { astrocytes, and } \\
\text { microglia cells }\end{array}$ & $\begin{array}{l}\text { Recapitulates } \\
\text { vascular-induced } \\
\text { GCSs invasion }\end{array}$ & $\begin{array}{l}\text {-Study of tumor invasion } \\
\text { and migration mechanisms } \\
\text { in the perivascular space }\end{array}$ & -Difficult scale-up & $\begin{array}{l}\text { Chonan et al. } \\
\text { (2017) }\end{array}$ \\
\hline & $\begin{array}{l}\text { Patient-derived } \\
\text { glioblastoma cells }\end{array}$ & HUVECS & $\begin{array}{l}\text { Fibrinogen and } \\
\text { Matrigel }\end{array}$ & No & $\begin{array}{l}\text { No, lacks pericytes, } \\
\text { astrocytes, and } \\
\text { microglia cells }\end{array}$ & $\begin{array}{l}\text { Recapitulates } \\
\text { vascular-induced } \\
\text { GCSs invasion }\end{array}$ & $\begin{array}{l}\text {-Study of tumor } \\
\text { vascularization } \\
\text { mechanisms } \\
\text { - Screening of tumor } \\
\text { vascularization inhibitors }\end{array}$ & & $\begin{array}{l}\text { Truong et al. } \\
\text { (2019) }\end{array}$ \\
\hline & $\begin{array}{l}\text { Rat and human } \\
\text { glioblastoma cell lines } \\
\text { (C-6, U251) }\end{array}$ & - & Collagen & Yes & $\begin{array}{l}\text { No, lacks ECs, } \\
\text { pericytes, }\end{array}$ & $\begin{array}{l}\text { Recapitulates both } \\
\text { tumor perivascular } \\
\text { and hypoxic niches }\end{array}$ & $\begin{array}{l}\text {-Study of tumor invasion } \\
\text { and migration mechanisms }\end{array}$ & & $\begin{array}{l}\text { Ayuso et al. } \\
(2017)\end{array}$ \\
\hline
\end{tabular}




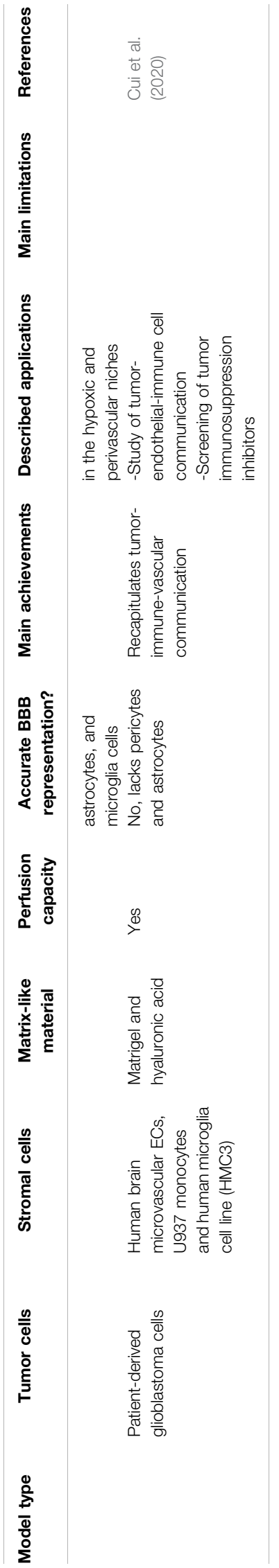

Some researchers described the association of homogeneous tumor spheroids with BBB models using Transwell ${ }^{\circledR}$ systems, where both are separated by a permeable membrane. For drugs that need to cross the $\mathrm{BBB}$ before tumor internalization, these models allow BBB permeability and tumor penetration/toxicity testing in a more biologically relevant manner, but they do not represent the GBM vascularized tissue (Belhadj et al., 2017; Marino et al., 2019; Sherman and Rossi, 2019). Nevertheless, in vitro studies conducted with $\mathrm{BBB}$ models co-cultured with GBM cell monolayers in Transwell ${ }^{\circledR}$ systems showed that tumor cells drive EC uncontrolled proliferation and disorganization, like the native focal sites of BBB disruption in GBM scenarios (Mendes et al., 2015). Therefore, there is the possibility that these alterations also occur in BBB models co-cultured with GBM spheroids, mimicking tumor and tumor-associated $\mathrm{BBB}$ separately, but more accurately.

\subsection{Scaffold-Based Models}

Cell cultures supported by biologically relevant matrices can create scaffold-based in vitro models, that attempt to mimic tumor biophysical environment. Given the previously described GBM ECM composition, Matrigel, collagen, fibrin and hyaluronic acid are the most frequently employed matrices to produce these models. In fact, studies reported that scaffold biophysical features, as stiffness, affects GBM stemness and, consequently, GBM chemotherapy resistance (Palamà et al., 2018; Xiao et al., 2020). So, these biomaterials mechanical properties have been manipulated to condition cellular behavior and create biomimetic models, including vascularized GBM models. Despite all the efforts made to capture tumors biophysical environment, this remains a great challenge. Multiple variables as porosity, polymer concentration, matrix elasticity must be simultaneously controlled to mimic natural tumor ECM (Vasudevan et al., 2020).

One of the first materials used as scaffold for in vitro models was Matrigel. In 1988, Kubota et al. found that human umbilical vein endothelial cells (HUVECs) on Matrigel attach and migrate towards each other forming long and complete capillary-like structures when supplemented with bovine calf serum and FGF, or only short and incomplete structures without any supplementation (Kubota et al., 1988). Because this capillary-like structures formation under certain conditions mimics the in vivo angiogenic process, Matrigel-based tubular networks assays emerged as useful tools to identify angiogenic signaling cascades and to assess new anti-angiogenic therapeutics (Benton et al., 2014).

Matrigel has also shown utility in the study of GSC transdifferentiation into ECs. A tubular network assay with patient-derived GBM cells cultured on Matrigel was used to characterize GSCs and verify their vascular development ability (Ke et al., 2020). In this case, patient cells were able to transdifferentiate into ECs and further form tubular structures. Using the same model, researchers also tested drugs capable of inhibiting this transdifferentiation process (Ke et al., 2020). Furthermore, patient-derived GBM cells cultured on Matrigel have also been used to study GBM recurrence and resistance mechanisms after radiotherapy. Apparently, radiotherapy enhances TDECs ability to form tubular structures in Matrigel, 
without increasing their proliferation rate (Deshors et al., 2019). Therefore, and as mentioned before, the increased vascularization capacity of TDECs may be one the mechanisms explaining GBM resistance and recurrence after radiotherapy. Considering these systems' power to study angiogenesis, GSC transdifferentiation and to test novel neovascularization inhibitors, we decided to include them in this section even though they do not represent vascularized tumor tissue per se.

\subsection{D-Bioprinted Models}

In the last decade, 3D bioprinting emerged has one of the strategies with greatest potential for in vitro models' development. In general, this technique consists of bioink printing, layer-by-layer, allowing the establishment of complex 3D living systems (Han et al., 2020). There are two bioink subtypes: one includes living cells within an exogenous biomaterial matrix, both printed simultaneously, and the other includes only living cells, which are printed within a cast structure and then produce their own ECM (Dai et al., 2016). In 3Dbioprinted GBM models, only the first bioink type has been used.

Printed cells usually include cancer cell lines or patientderived tumor cells, ECs, fibroblasts or immune cells, while alginate, gelatin, polyethyleneglycol (PEG) methacrylate or decellularized ECM comprise the models' matrix. These models are usually very reproducible and adjustable since their production is entirely dependent on computer programs and no human manipulation is directly involved (Tang et al., 2021). In contrast with 2D cell cultures, 3D-bioprinted models maintain in vivo stemness properties, gene expression and vascularization tendency. Furthermore, they allow the manipulation of a specific factor to study its role in tumor biology (Ruiz-Garcia et al., 2020).

Recently, 3D bioprinting has revealed its applicability and usefulness in the neuro-oncology field, specifically in the assembly of GBM in vitro models to study neovascularization. Both GBM cells and ECs bioprinted within ECM-like materials sprout, forming tubular structures (Figure 4) (Table 1) (Han et al., 2020; Tang et al., 2021). Moreover, pro-angiogenic genes expression and cells' sprouting is regulated by matrix biophysical properties, such as stiffness (Tang et al., 2021). Therefore, these models mimic in vivo angiogenesis and GSCs transdifferentiation.

In vivo behavior of tumor cells is also maintained in vascularized bioprinted models, in contrast to what is observed in other models. In vascularized bioprinted models, tumor cells are more invasive and resistant to therapy, which might be a result of vascular derived signaling cues (Figure 5) (Table 1) (Yi et al., 2019; Ozturk et al., 2020). Thereby, these models are useful in drug research and they may eventually help guiding clinical decisions.

Although none of the developed GBM vascularized models has been explored to study cell-cell interaction, we believe this is a potential future application. For instance, Heirinch et al. used a 3D bioprinted GBM model to study GBM and immunologic cells crosstalk (Heinrich et al., 2019).

Microfluidics integration with bioprinting is an emergent strategy to generate completer and more biomimetic models. For instance, microfluidic chips can be manufactured and cultured through 3D-bioptinting, generating more dynamic, flexible and reproducible systems (Datta et al., 2020).
Other recently reported bioprinted models include GBM cells and stromal cells other than ECs, as macrophages (Grolman et al., 2015; Heinrich et al., 2019). These models allow the communication between different TME cells and the testing of drugs targeting this intercellular communication. Therefore, in the future, it is possible for these models to become more complete, dynamic and closer to the native TME.

Perfusable in vitro models could also be useful to study drug transport and distribution kinetics, after its inclusion in a microcirculatory system. In line with this, platforms have already been designed to mimic drug transport in the bloodstream and passage through vessel walls, followed by crossing of the interstitial fluid and entry into tumor cells (Cao et al., 2019). In the future, it would be interesting if these types of models could be adapted to represent GBM and to assess drug distribution after intravenous administration.

\subsection{Microfluidic-Based Models}

To date, one of the most promising alternatives for in vitro modeling of vascularized tissue is the use of microfluidic systems-based models. Microfluidic systems are devices with networks of micro-channels where liquids can flow in controlled manners. Usually the channels are made of biocompatible materials as polydimethylsiloxane (PDMS), PEG or polystyrene (PS). Their biocompatibility along with other desirable features, such as easy tunability and cost-effectiveness, promoted the association of these platforms with tissue engineering methods to recreate the complex human physiology-the so called organ-on-a-chip technology (Bhatia and Ingber, 2014). Compared with spheroids or non-bioprinted scaffold-based models, microfluidic-based models are less variable in terms of size and shape (Bhatia and Ingber, 2014). Furthermore, in these models, cells are exposed to mechanical signals, such as tension, compression or microvascular blood flow shear stress (1-10 dyne $\left./ \mathrm{cm}^{3}\right)$, thus offering the possibility to overcome the limitations of non-perfusable models (Kim et al., 2013).

Similar to other models, organ-on-a-chip technology has been employed in the establishment of in vitro GBM vascularized models, useful in studies of fundamental biology, such as tumorassociated vascularization processes. Usually, different channels are cultured with tumor cells or ECs, allowing their communication without direct contact. Through paracrine communication, tumor cells induce perfusable microvascular networks development (Table 1) (Kim et al., 2013; Truong et al., 2019). Thus, enabling neovascularization processes study. With the incorporation of patient-derived cells, researchers can study neovascularization processes from an individual perspective (Figure 6) (Table 1) (Amemiya et al., 2021). Furthermore, these models are useful for the study of tumor cells behavior in perivascular niche, namely migration and invasion towards vascular elements (Table 1) (Ayuso et al., 2017; Chonan et al., 2017; Truong et al., 2019).

By co-culturing tumor cells and endothelial cells in distinct channels (Table 1), it was observed tumor cell migration and invasion towards vascular structures. Furthermore, researchers identified the SDF-1 signaling pathway as a major contributor for GSC invasion. Through binding to its receptor, CXCR4, 
A

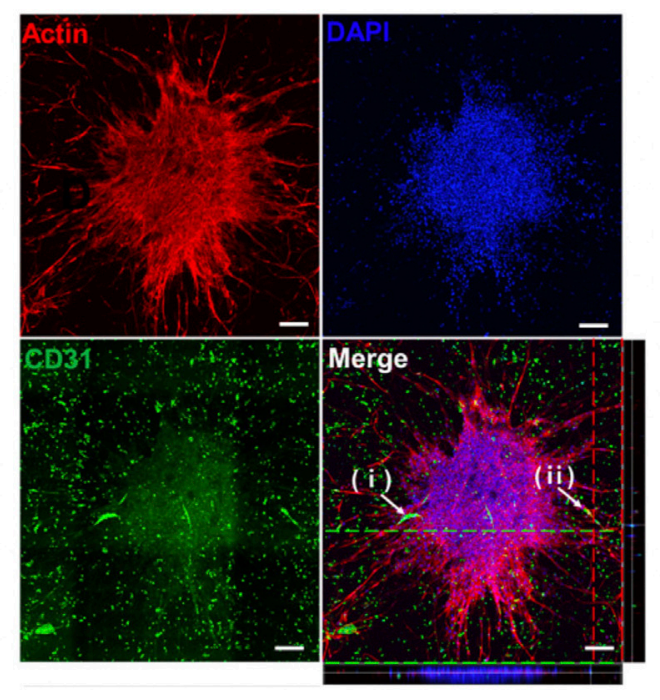

B
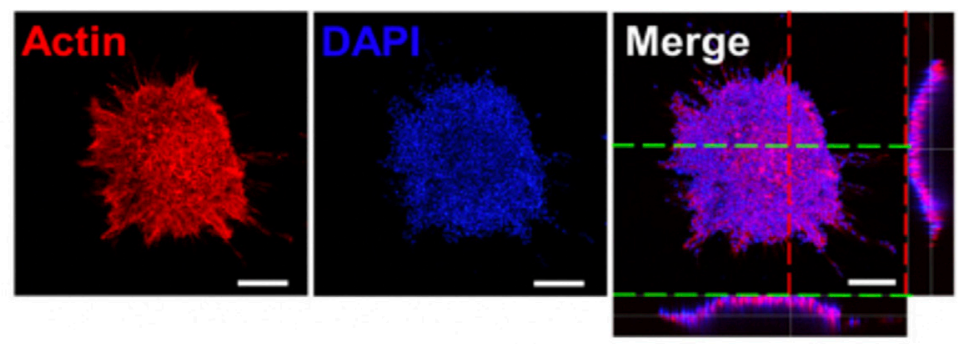

C

D

E
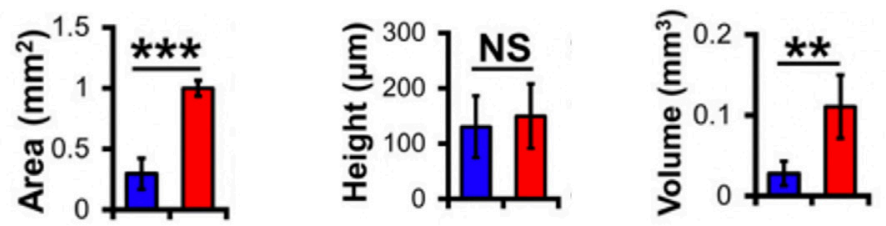

FIGURE 4 | - (A) Confocal images of U87 MG spheroids within a bioprinted vascularized hydrogel. (i) and (ii) white arrows indicate hydrogel vessels invading and infiltrating into the spheroids. 4,6-diamino-2-phenylindole (DAPI) was used as a cell nuclei marker and platelet endothelial cell adhesion molecule 1 (CD31) was used as an EC marker. (B) Confocal images of U87 MG spheroids without vascularized hydrogel. The white bar corresponds to a 200 m length. (C) Area of spheroids measured with (red) and without (blue) vascularized hydrogel. (D) Height of spheroids measured with (red) and without (blue) vascularized hydrogel. (E) Volume of spheroids measured with (red) and without (blue) vascularized hydrogel. ${ }^{\star \star}$ and ${ }^{\star \star \star}$ means $p$ value $<0.01,0.001$, respectively, and NS means not significant. Reproduced with permission from (Han et al., 2020).

endothelial SDF-1 promoted GSC invasion, whereas GSC treatment with a CXCR4 inhibitor significantly reduced their invasion (Truong et al., 2019). Therefore, microfluidic-based models not only are able to recapitulate the typical architecture of the GBM perivascular niche, but are also suitable for drug screening purposes, especially to test drugs that interfere with endothelial-tumor cell communication.

In addition, microfluidic-based models are promising tools to represent and study GBM hypoxic niches. By blocking the channels that are feeding tumor cells, it was observed the migration of tumor cells towards the opposite direction (Table 1) (Ayuso et al., 2017).

Finally, we would also like to point out that other stromal elements have been included in microfluidic-based GBM models, bringing them closer to the in vivo tumor. Indeed, Cui et al. engineered a sophisticated microfluidic system including not only patient-derived cells and endothelial cells, but also immune cells. Macrophages and tumor cells incorporated a spheroid while $\mathrm{T}$ cells were circulating in an adjacent channel (Table 1). This model generated a GBM immunosuppressive heterogeneous microenvironment since $\mathrm{T}$ human cells extravasation and infiltration was variable between patients and dependent on tumor-immune-vascular cell crosstalk. Apparently, macrophages present within the tumor acquired an antiinflammatory phenotype, inhibiting $\mathrm{T}$ cell extravasation and infiltration. Nevertheless, $T$ cells were found in most of the tumors, but they were inactive. Cui et al.'s model also helped to monitor real-time immune cell activity and response to several immunotherapies (Cui et al., 2020).
Taking in consideration their applicability, microfluidic-based models present an unquestionable value in biomedical research. They can accelerate the identification of novel biomarkers/ therapeutic targets and personalized therapeutic strategies. However, these systems face same limitations too. There is a limited control over their size and over the arrangement of different cell types within the system (Yu et al., 2019). Their use depends on several other equipment, namely pumps and valves (Yu et al., 2019). Furthermore, scale-up is difficult. So, in the future, we believe new and improved microfluidic systems will emerge to overcome these limitations.

\section{DISCUSSION}

Rapidly growing tumor cells need additional amounts of oxygen and nutrients to sustain their metabolism, leading to vascular proliferation and to the development of an abnormal and dysfunctional vascular system, which consists of a GBM characteristic. Despite being aberrant, GBM blood vessels ensure tumor cell maintenance, contributing to tumor survival and to its poor prognosis. GBM vascularization mechanisms involve angiogenesis, vessel co-option, vasculogenesis, vascular mimicry and transdifferentiation. As each one of them is activated by different signals, current antiangiogenic therapies drive a transient vasculature normalization, which is not effective.

In addition to its transport functions, the GBM perivascular niche also supports GSC self-renewal and invasion, promotes macrophage activation towards a pro-tumoral phenotype, and 


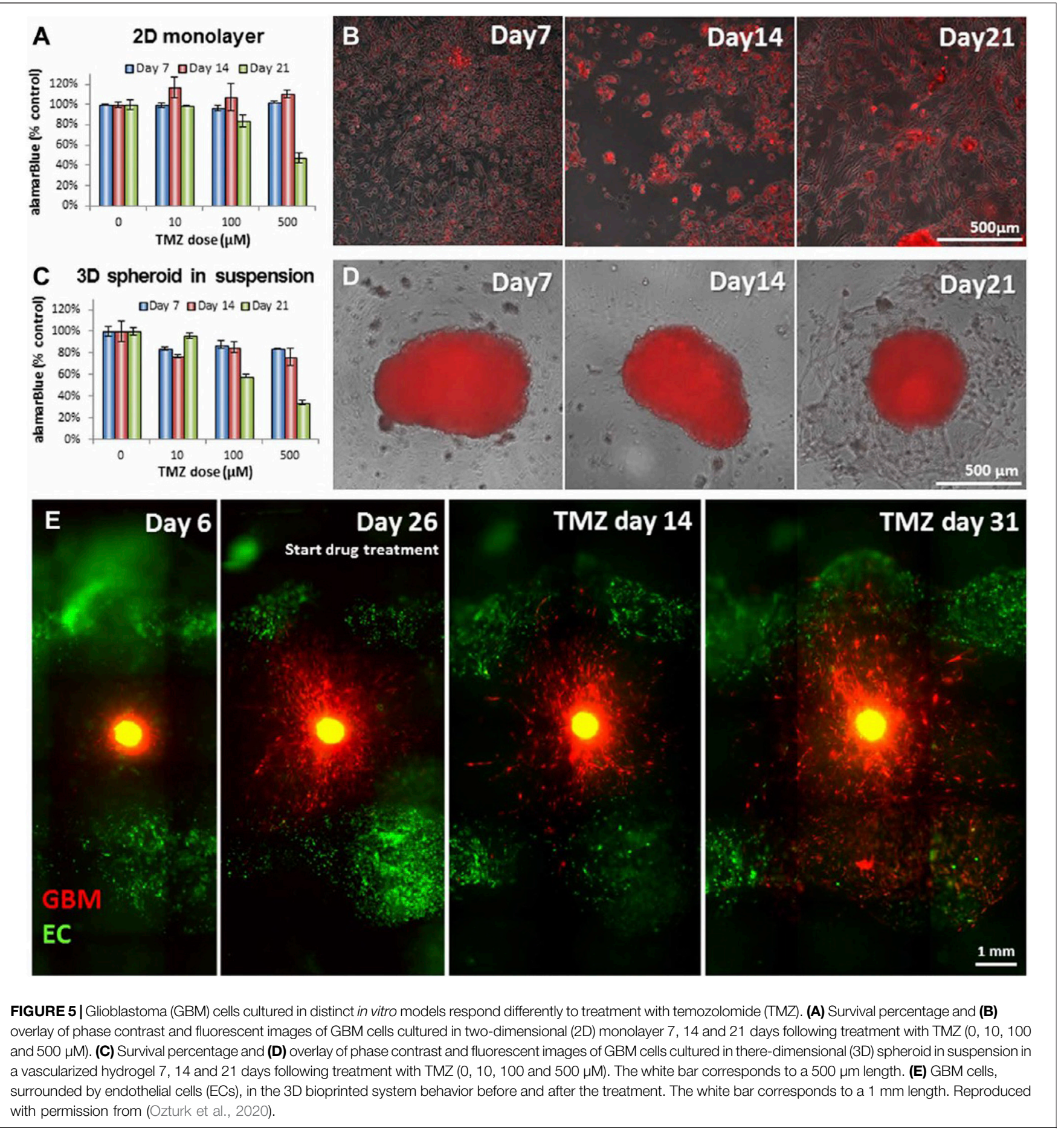

enhances ECM remodeling, which are all key in tumor progression and invasiveness. Therefore, understanding the complex communications between tumor vasculature and other TME elements is critical to find new and relevant therapeutic targets and to develop effective anti-GBM treatments.

In the last years, major innovations in microscale tissue engineering technologies enabled a breakthrough in 3D tumor model assembly, particularly in the development of vascularized tumor models. 3D models can include various cell populations and mimic native tumor features, such as oxygen/nutrient gradients and tumor cell communication with the surrounding microenvironment. Some of the recently established, spherical, scaffold or microfluidic-based 3D models can even resemble neovascularization processes, thus holding the potential to be a proper tool for the identification of new therapeutic targets. Moreover, they can be used to test anti- 


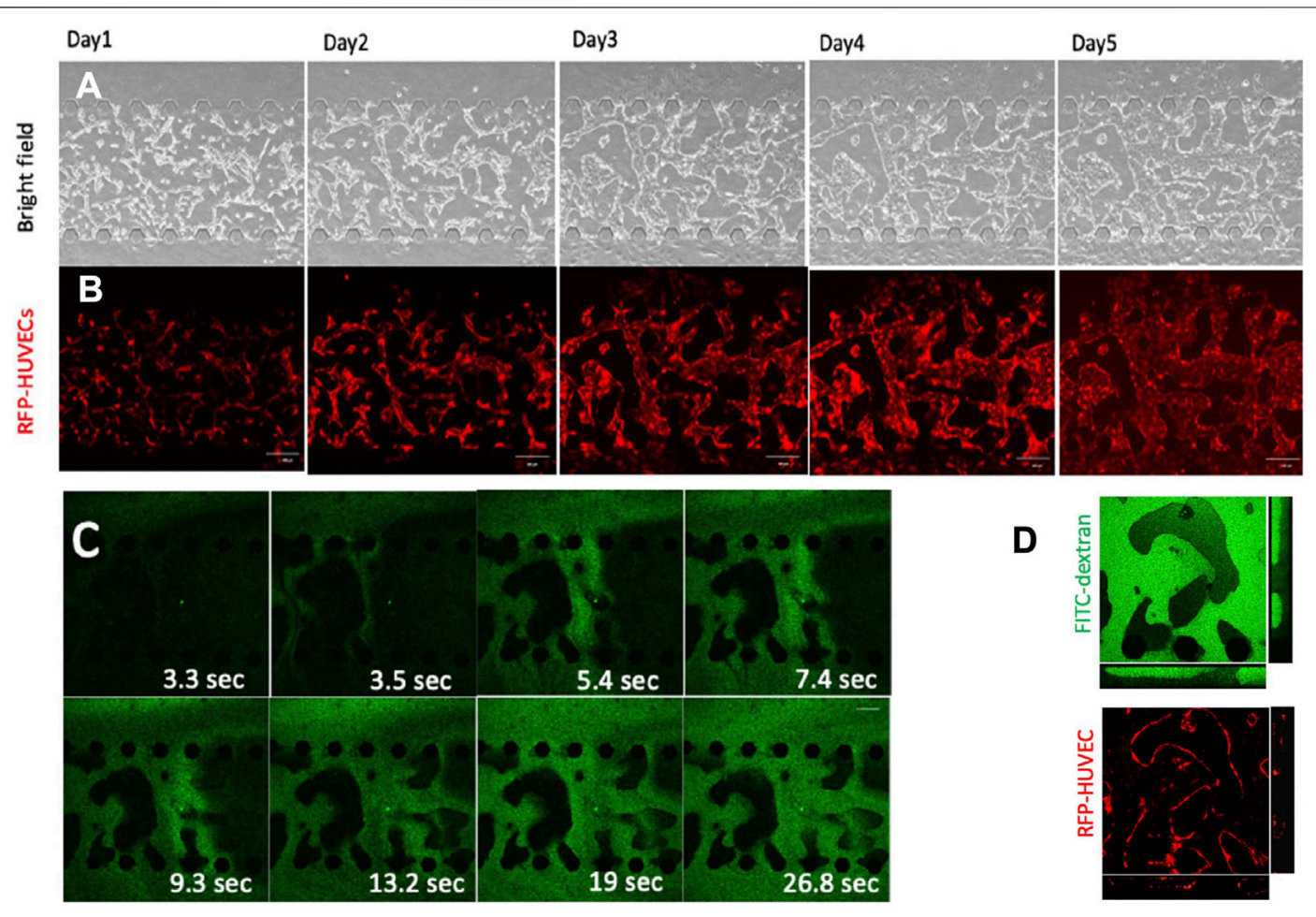

FIGURE 6 | - Perfusable microvascular network formation in microfluidic devices. (A) Bright field and (B) confocal fluorescent microscopy images of red fluorescent protein (RFP) expressing human umbilical vein endothelial cells (HUVECs) at days 1, 2, 3, 4 and 5 following culture in a microfluidic device. The white bar corresponds to a $200 \mu \mathrm{m}$ length. (C) Time-lapse images of a microfluidic device channel cultivated with HUVECs after injection of fluorescein isothiocyanate (FITC) dextran. (D) Confocal fluorescent microscopy images amplification after FITC dextran injection. HUVECs and FITC dextran are represented in red and green, respectively. Reproduced with permission from (Amemiya et al., 2021).

tumor drugs in a more physiologically relevant setting, especially neovascularization inhibitors, accelerating their clinical translation.

Despite all the advances in 3D vascularized GBM models, there is still room for improvement. In the future, alternative types of stromal cells, and even autologous stromal cells, might be incorporated into these models for long-term use and largescale drug screening. Moreover, the growing use of 3D models may lead to the development of more sophisticated techniques that will allow researchers to monitor models' behavior, non-invasively.

Possibly, other strategies as 4D bioprinting, might be used in these models' construction. 4D-bioprinting is similar to $3 \mathrm{D}$ bioprinting but incorporates a fourth dimension-time through the use of stimuli-responsive biomaterials (Gao et al., 2016). After printing, these biomaterials respond to external factors, as temperature, humidity or $\mathrm{pH}$, modifying their shape (Yang et al., 2019). The purpose is to pre-define systems behavior through the materials selection generating dynamic constructs (Gao et al., 2016). 4D bioprinting has already revealed encouraging results in in vitro production of self-assembled tubes with highly controlled architecture and diameter and supporting cell viability (Kirillova et al., 2017). Therefore, eventually, this technique can be employed in the assembly of vascularized GBM models and enhance their biologic reliability.

\section{AUTHOR CONTRIBUTIONS}

$\mathrm{CP}$-Conceptualization, writing the original draft. $\mathrm{CM}$-Conceptualization, writing the original draft and reviewing. JM-discussion and reviewing. FB-supervision and reviewing. BMC-supervision and reviewing. BSconceptualization, supervision and reviewing.

\section{FUNDING}

This work was financed by Institute of Research and Advanced Training in Health Sciences and Technology (IINFACTS) through "Projetos Integrativos 2021"-PI-2RL in the framework of the project "GBM-Multi3D." CP acknowledges CESPU for the BD fellowship and Fundação para a Ciência e Tecnologia for the PhD fellowship SFRH/BD/06611/2020.

\section{ACKNOWLEDGMENTS}

$\mathrm{CP}$ and CM gratefully acknowledge Fundação para a Ciência e Tecnologia (FCT), Portugal, for financial support (SFRH/BD/ 06611/2020 and SFRH/BD/137946/2018). 


\section{REFERENCES}

Allen, M., Bjerke, M., Edlund, H., Nelander, S., and Westermark, B. (2016). Origin of the U87MG Glioma Cell Line: Good News and Bad News. Sci. Transl. Med. 8 (354), 354re353. doi:10.1126/scitranslmed.aaf6853

Amemiya, T., Hata, N., Mizoguchi, M., Yokokawa, R., Kawamura, Y., Hatae, R., et al. (2021). Mesenchymal Glioblastoma-Induced Mature De-novo Vessel Formation of Vascular Endothelial Cells in a Microfluidic Device. Mol. Biol. Rep. 48 (1), 395-403. doi:10.1007/s11033-020-06061-7

Arvanitis, C. D., Ferraro, G. B., and Jain, R. K. (2020). The Blood-Brain Barrier and Blood-Tumour Barrier in Brain Tumours and Metastases. Nat. Rev. Cancer 20 (1), 26-41. doi:10.1038/s41568-019-0205-x

Ayuso, J. M., Monge, R., Martínez-González, A., Virumbrales-Muñoz, M., Llamazares, G. A., Berganzo, J., et al. (2017). Glioblastoma on a Microfluidic Chip: Generating Pseudopalisades and Enhancing Aggressiveness through Blood Vessel Obstruction Events. Neuonc 19 (4), now230-513. doi:10.1093/neuonc/now230

Bao, S., Wu, Q., Sathornsumetee, S., Hao, Y., Li, Z., Hjelmeland, A. B., et al. (2006). Stem Cell-like Glioma Cells Promote Tumor Angiogenesis through Vascular Endothelial Growth Factor. Cancer Res. 66 (16), 7843-7848. doi:10.1158/00085472.Can-06-1010

Becher, O. J., Hambardzumyan, D., Fomchenko, E. I., Momota, H., Mainwaring, L., Bleau, A.-M., et al. (2008). Gli Activity Correlates with Tumor Grade in Platelet-Derived Growth Factor-Induced Gliomas. Cancer Res. 68 (7), 2241-2249. doi:10.1158/0008-5472.Can-07-6350

Behnan, J., Finocchiaro, G., and Hanna, G. (2019). The Landscape of the Mesenchymal Signature in Brain Tumours. Brain 142 (4), 847-866. doi:10. 1093/brain/awz044

Belhadj, Z., Zhan, C., Ying, M., Wei, X., Xie, C., Yan, Z., et al. (2017). Multifunctional Targeted Liposomal Drug Delivery for Efficient Glioblastoma Treatment. Oncotarget 8 (40), 66889-66900. doi:10.18632/ oncotarget.17976

Belousov, A., Titov, S., Shved, N., Garbuz, M., Malykin, G., Gulaia, V., et al. (2019). The Extracellular Matrix and Biocompatible Materials in Glioblastoma Treatment. Front. Bioeng. Biotechnol. 7, 341. doi:10.3389/fbioe.2019.00341

Benton, G., Arnaoutova, I., George, J., Kleinman, H. K., and Koblinski, J. (2014). Matrigel: from Discovery and ECM Mimicry to Assays and Models for Cancer Research. Adv. Drug Deliv. Rev. 79-80, 3-18. doi:10.1016/j.addr.2014.06.005

Bhaduri, A., Di Lullo, E., Jung, D., Müller, S., Crouch, E. E., Espinosa, C. S., et al. (2020). Outer Radial Glia-like Cancer Stem Cells Contribute to Heterogeneity of Glioblastoma. Cell Stem Cell 26 (1), 48-63. e46. doi:10.1016/j.stem.2019.11.015

Bhatia, S. N., and Ingber, D. E. (2014). Microfluidic Organs-On-Chips. Nat. Biotechnol. 32 (8), 760-772. doi:10.1038/nbt.2989

Bilozur, M. E., and Hay, E. D. (1988). Neural Crest Migration in 3D Extracellular Matrix Utilizes Laminin, Fibronectin, or Collagen. Dev. Biol. 125 (1), 19-33. doi:10.1016/0012-1606(88)90055-3

Bohn, A., Braley, A., Rodriguez de la Vega, P., Zevallos, J. C., and Barengo, N. C. (2018). The Association between Race and Survival in Glioblastoma Patients in the US: A Retrospective Cohort Study. PLoS One 13 (6), e0198581. doi:10.1371/ journal.pone.0198581

Bouterfa, H., Darlapp, A.-R., Klein, E., Pietsch, T., Roosen, K., and Tonn, J. C. (1999). Expression of Different Extracellular Matrix Components in Human Brain Tumor and Melanoma Cells in Respect to Variant Culture Conditions. J. Neurooncol. 44 (1), 23-33. doi:10.1023/a:1006331416283

Bouterfa, H., Janka, M., Meese, E., Kerkau, S., Roosen, K., and Tonn, J. C. (1997). Effect of Changes in the CD44 Gene on Tumour Cell Invasion in Gliomas. Neuropathol. Appl. Neurobiol. 23 (5), 373-379. doi:10.1046/j.1365-2990.1997. 00067.x

Brem, S. (1976). The Role of Vascular Proliferation in the Growth of Brain Tumors. Clin. Neurosurg. 23, 440-453. doi:10.1093/neurosurgery/23.cn_suppl_1.440

Broekgaarden, M., Bulin, A.-L., Porret, E., Musnier, B., Chovelon, B., Ravelet, C., et al. (2020). Surface Functionalization of Gold Nanoclusters with Arginine: a Trade-Off between Microtumor Uptake and Radiotherapy Enhancement. Nanoscale 12 (13), 6959-6963. doi:10.1039/d0nr01138j

Brooks, L. J., and Parrinello, S. (2017). Vascular Regulation of Glioma Stem-like Cells: a Balancing Act. Curr. Opin. Neurobiol. 47, 8-15. doi:10.1016/j.conb. 2017.06.008
Calabrese, C., Poppleton, H., Kocak, M., Hogg, T. L., Fuller, C., Hamner, B., et al. (2007). A Perivascular Niche for Brain Tumor Stem Cells. Cancer Cell 11 (1), 69-82. doi:10.1016/j.ccr.2006.11.020

Cao, X., Ashfaq, R., Cheng, F., Maharjan, S., Li, J., Ying, G., et al. (2019). A Tumoron-a-Chip System with Bioprinted Blood and Lymphatic Vessel Pair. Adv. Funct. Mater. 29 (31), 1807173. doi:10.1002/adfm.201807173

Cassetta, L., and Pollard, J. W. (2018). Targeting Macrophages: Therapeutic Approaches in Cancer. Nat. Rev. Drug Discov. 17 (12), 887-904. doi:10. 1038/nrd.2018.169

Charles, N., Ozawa, T., Squatrito, M., Bleau, A.-M., Brennan, C. W., Hambardzumyan, D., et al. (2010). Perivascular Nitric Oxide Activates Notch Signaling and Promotes Stem-like Character in PDGF-Induced Glioma Cells. Cell Stem Cell 6 (2), 141-152. doi:10.1016/j.stem.2010.01.001

Chonan, Y., Taki, S., Sampetrean, O., Saya, H., and Sudo, R. (2017). Endotheliuminduced Three-Dimensional Invasion of Heterogeneous Glioma Initiating Cells in a Microfluidic Coculture Platform. Integr. Biol. 9 (9), 762-773. doi:10.1039/ c7ib00091j

Cohen, M. H., Shen, Y. L., Keegan, P., and Pazdur, R. (2009). FDA Drug Approval Summary: Bevacizumab (Avastin) as Treatment of Recurrent Glioblastoma Multiforme. Oncologist 14 (11), 1131-1138. doi:10.1634/theoncologist.20090121

Cui, X., Ma, C., Vasudevaraja, V., Serrano, J., Tong, J., Peng, Y., et al. (2020). Dissecting the Immunosuppressive Tumor Microenvironments in Glioblastoma-On-A-Chip for Optimized PD-1 Immunotherapy. Elife 9. doi:10.7554/eLife.52253

Cui, X., Morales, R.-T. T., Qian, W., Wang, H., Gagner, J.-P., Dolgalev, I., et al. (2018). Hacking Macrophage-Associated Immunosuppression for Regulating Glioblastoma Angiogenesis. Biomaterials 161, 164-178. doi:10.1016/j. biomaterials.2018.01.053

Dai, X., Ma, C., Lan, Q., and Xu, T. (2016). 3D Bioprinted Glioma Stem Cells for Brain Tumor Model and Applications of Drug Susceptibility. Biofabrication 8 (4), 045005. doi:10.1088/1758-5090/8/4/045005

Daneman, R., and Prat, A. (2015). The Blood-Brain Barrier. Cold Spring Harb Perspect. Biol. 7 (1), a020412. doi:10.1101/cshperspect.a020412

Das, S., and Marsden, P. A. (2013). Angiogenesis in Glioblastoma. N. Engl. J. Med. 369 (16), 1561-1563. doi:10.1056/NEJMcibr1309402

Datta, P., Dey, M., Ataie, Z., Unutmaz, D., and Ozbolat, I. T. (2020). 3D Bioprinting for Reconstituting the Cancer Microenvironment. Npj Precis. Onc. 4, 18. doi:10. 1038/s41698-020-0121-2

de Gooijer, M. C., Guillén Navarro, M., Bernards, R., Wurdinger, T., and van Tellingen, O. (2018). An Experimenter's Guide to Glioblastoma Invasion Pathways. Trends Mol. Med. 24 (9), 763-780. doi:10.1016/j.molmed.2018. 07.003

de Groot, J. F., Fuller, G., Kumar, A. J., Piao, Y., Eterovic, K., Ji, Y., et al. (2010). Tumor Invasion after Treatment of Glioblastoma with Bevacizumab: Radiographic and Pathologic Correlation in Humans and Mice. NeuroOncology 12 (3), 233-242. doi:10.1093/neuonc/nop027

De Palma, M., Venneri, M. A., Galli, R., Sergi, L. S., Politi, L. S., Sampaolesi, M., et al. (2005). Tie2 Identifies a Hematopoietic Lineage of Proangiogenic Monocytes Required for Tumor Vessel Formation and a Mesenchymal Population of Pericyte Progenitors. Cancer Cell 8 (3), 211-226. doi:10.1016/ j.ccr.2005.08.002

Delpech, B., Maingonnat, C., Girard, N., Chauzy, C., Olivier, A., Maunoury, R., et al. (1993). Hyaluronan and Hyaluronectin in the Extracellular Matrix of Human Brain Tumour Stroma. Eur. J. Cancer 29 (7), 1012-1017. doi:10.1016/ s0959-8049(05)80214-x

Deshors, P., Toulas, C., Arnauduc, F., Malric, L., Siegfried, A., Nicaise, Y., et al. (2019). Ionizing Radiation Induces Endothelial Transdifferentiation of Glioblastoma Stem-like Cells through the Tie2 Signaling Pathway. Cell Death Dis 10 (11), 816. doi:10.1038/s41419-019-2055-6

Du, R., Lu, K. V., Petritsch, C., Liu, P., Ganss, R., Passegué, E., et al. (2008). HIFla Induces the Recruitment of Bone Marrow-Derived Vascular Modulatory Cells to Regulate Tumor Angiogenesis and Invasion. Cancer Cell 13 (3), 206-220. doi:10.1016/j.ccr.2008.01.034

Edwards, L. A., Woolard, K., Son, M. J., Li, A., Lee, J., Ene, C., et al. (2011). Effect of Brain- and Tumor-Derived Connective Tissue Growth Factor on Glioma Invasion. J. Natl. Cancer Inst. 103 (15), 1162-1178. doi:10.1093/jnci/djr224 
El Hallani, S., Boisselier, B., Peglion, F., Rousseau, A., Colin, C., Idbaih, A., et al. (2010). A New Alternative Mechanism in Glioblastoma Vascularization: Tubular Vasculogenic Mimicry. Brain 133 (Pt 4), 973-982. doi:10.1093/ brain/awq044

Ellert-Miklaszewska, A., Poleszak, K., Pasierbinska, M., and Kaminska, B. (2020). Integrin Signaling in Glioma Pathogenesis: From Biology to Therapy. Ijms 21 (3), 888. doi:10.3390/ijms21030888

Ferdowsian, H. R., and Beck, N. (2011). Ethical and Scientific Considerations Regarding Animal Testing and Research. PLoS One 6 (9), e24059. doi:10.1371/ journal.pone.0024059

Fessler, E., Borovski, T., and Medema, J. P. (2015). Endothelial Cells Induce Cancer Stem Cell Features in Differentiated Glioblastoma Cells via bFGF. Mol. Cancer 14, 157. doi:10.1186/s12943-015-0420-3

Forsyth, P. A., Wong, H., Laing, T. D., Rewcastle, N. B., Morris, D. G., Muzik, H., et al. (1999). Gelatinase-A (MMP-2), Gelatinase-B (MMP-9) and Membrane Type Matrix Metalloproteinase-1 (MT1-MMP) Are Involved in Different Aspects of the Pathophysiology of Malignant Gliomas. Br. J. Cancer 79 (1112), 1828-1835. doi:10.1038/sj.bjc.6690291

Fu, L.-Q., Du, W.-L., Cai, M.-H., Yao, J.-Y., Zhao, Y.-Y., and Mou, X.-Z. (2020). The Roles of Tumor-Associated Macrophages in Tumor Angiogenesis and Metastasis. Cell Immunol. 353, 104119. doi:10.1016/j.cellimm.2020.104119

Gao, B., Yang, Q., Zhao, X., Jin, G., Ma, Y., and Xu, F. (2016). 4D Bioprinting for Biomedical Applications. Trends Biotechnol. 34 (9), 746-756. doi:10.1016/j. tibtech.2016.03.004

Gilbert, M. R., Dignam, J. J., Armstrong, T. S., Wefel, J. S., Blumenthal, D. T., Vogelbaum, M. A., et al. (2014). A Randomized Trial of Bevacizumab for Newly Diagnosed Glioblastoma. N. Engl. J. Med. 370 (8), 699-708. doi:10.1056/ NEJMoa1308573

Gómez-Oliva, R., Domínguez-García, S., Carrascal, L., Abalos-Martínez, J., Pardillo-Díaz, R., Verástegui, C., et al. (2020). Evolution of Experimental Models in the Study of Glioblastoma: Toward Finding Efficient Treatments. Front. Oncol. 10, 614295. doi:10.3389/fonc.2020.614295

Griveau, A., Seano, G., Shelton, S. J., Kupp, R., Jahangiri, A., Obernier, K., et al. (2018). A Glial Signature and Wnt7 Signaling Regulate Glioma-Vascular Interactions and Tumor Microenvironment. Cancer Cell 33 (5), 874-889. e877. doi:10.1016/j.ccell.2018.03.020

Grolman, J. M., Zhang, D., Smith, A. M., Moore, J. S., and Kilian, K. A. (2015). Rapid 3D Extrusion of Synthetic Tumor Microenvironments. Adv. Mater. 27 (37), 5512-5517. doi:10.1002/adma.201501729

Guan, X., Hasan, M. N., Maniar, S., Jia, W., and Sun, D. (2018). Reactive Astrocytes in Glioblastoma Multiforme. Mol. Neurobiol. 55 (8), 6927-6938. doi:10.1007/ s12035-018-0880-8

Guyon, J., Chapouly, C., Andrique, L., Bikfalvi, A., and Daubon, T. (2021). The Normal and Brain Tumor Vasculature: Morphological and Functional Characteristics and Therapeutic Targeting. Front. Physiol. 12, 622615. doi:10.3389/fphys.2021.622615

Hambardzumyan, D., Gutmann, D. H., and Kettenmann, H. (2016). The Role of Microglia and Macrophages in Glioma Maintenance and Progression. Nat. Neurosci. 19 (1), 20-27. doi:10.1038/nn.4185

Han, S., Kim, S., Chen, Z., Shin, H. K., Lee, S.-Y., Moon, H. E., et al. (2020). 3D Bioprinted Vascularized Tumour for Drug Testing. Ijms 21 (8), 2993. doi:10. 3390/ijms21082993

Hardee, M. E., and Zagzag, D. (2012). Mechanisms of Glioma-Associated Neovascularization. Am. J. Pathol. 181 (4), 1126-1141. doi:10.1016/j.ajpath. 2012.06.030

Heinrich, M. A., Bansal, R., Lammers, T., Zhang, Y. S., Michel Schiffelers, R., and Prakash, J. (2019). 3D-Bioprinted Mini-Brain: A Glioblastoma Model to Study Cellular Interactions and Therapeutics. Adv. Mater. 31 (14), 1806590. doi:10. 1002/adma.201806590

Henke, E., Nandigama, R., and Ergün, S. (2019). Extracellular Matrix in the Tumor Microenvironment and its Impact on Cancer Therapy. Front. Mol. Biosci. 6, 160. doi: $10.3389 /$ fmolb. 2019.00160

Hotchkiss, K. A., Ashton, A. W., and Schwartz, E. L. (2003). Thymidine Phosphorylase and 2-Deoxyribose Stimulate Human Endothelial Cell Migration by Specific Activation of the Integrins $\alpha 5 \beta 1$ and $\alpha \mathrm{V} \beta 3$. J. Biol. Chem. 278 (21), 19272-19279. doi:10.1074/jbc.M212670200

Hubbard, M. E., Arnold, S., Bin Zahid, A., McPheeters, M., Gerard O'Sullivan, M., Tabaran, A.-F., et al. (2018). Naturally Occurring Canine Glioma as a Model for
Novel Therapeutics. Cancer Invest. 36 (8), 415-423. doi:10.1080/07357907. 2018.1514622

Infanger, D. W., Cho, Y., Lopez, B. S., Mohanan, S., Liu, S. C., Gursel, D., et al. (2013). Glioblastoma Stem Cells Are Regulated by Interleukin-8 Signaling in a Tumoral Perivascular Niche. Cancer Res. 73 (23), 7079-7089. doi:10.1158/ 0008-5472.Can-13-1355

Jacob, F., Salinas, R. D., Zhang, D. Y., Nguyen, P. T. T., Schnoll, J. G., Wong, S. Z. H., et al. (2020). A Patient-Derived Glioblastoma Organoid Model and Biobank Recapitulates Inter- and Intra-tumoral Heterogeneity. Cell 180 (1), 188-204. e122. doi:10.1016/j.cell.2019.11.036

Kane, J. R. (2019). The Role of Brain Vasculature in Glioblastoma. Mol. Neurobiol. 56 (9), 6645-6653. doi:10.1007/s12035-019-1561-y

Kawataki, T., Yamane, T., Naganuma, H., Rousselle, P., Andurén, I., Tryggvason, K., et al. (2007). Laminin Isoforms and Their Integrin Receptors in Glioma Cell Migration and Invasiveness: Evidence for a Role of $\alpha 5$-laminin(s) and $\alpha 3 \beta 1$ Integrin. Exp. Cel Res. 313 (18), 3819-3831. doi:10.1016/j.yexcr.2007.07.038

Ke, C., Luo, J. r., Cen, Z. w., Li, Y., Cai, H. p., Wang, J., et al. (2020). Dual Antivascular Function of Human Fibulin-3 Variant, a Potential New Drug Discovery Strategy for Glioblastoma. Cancer Sci. 111 (3), 940-950. doi:10.1111/ cas. 14300

Kim, S.-J., Lee, H. J., Kim, M. S., Choi, H. J., He, J., Wu, Q., et al. (2015). Macitentan, a Dual Endothelin Receptor Antagonist, in Combination with Temozolomide Leads to Glioblastoma Regression and Long-Term Survival in Mice. Clin. Cancer Res. 21 (20), 4630-4641. doi:10.1158/1078-0432.Ccr-14-3195

Kim, S., Lee, H., Chung, M., and Jeon, N. L. (2013). Engineering of Functional, Perfusable 3D Microvascular Networks on a Chip. Lab. Chip 13 (8), 1489-1500. doi:10.1039/c3lc41320a

Kirillova, A., Maxson, R., Stoychev, G., Gomillion, C. T., and Ionov, L. (2017). 4D Biofabrication Using Shape-Morphing Hydrogels. Adv. Mater. 29 (46), 1703443. doi:10.1002/adma.201703443

Konduri, S., Lakka, S., Tasiou, A., Yanamandra, N., Gondi, C., Dinh, D., et al. (2001). Elevated Levels of Cathepsin B in Human Glioblastoma Cell Lines. Int. J. Oncol. 19 (3), 519-524. doi:10.3892/ijo.19.3.519

Koochekpour, S., Pilkington, G. J., and Merzak, A. (1995). Hyaluronic acid/CD44H Interaction Induces Cell Detachment and Stimulates Migration and Invasion of Human Glioma Cellsin Vitro. Int. J. Cancer 63 (3), 450-454. doi:10.1002/ijc. 2910630325

Ku, M.-C., Wolf, S. A., Respondek, D., Matyash, V., Pohlmann, A., Waiczies, S., et al. (2013). GDNF Mediates Glioblastoma-Induced Microglia Attraction but Not Astrogliosis. Acta Neuropathol. 125 (4), 609-620. doi:10.1007/s00401-013-1079-8

Kubota, Y., Kleinman, H. K., Martin, G. R., and Lawley, T. J. (1988). Role of Laminin and Basement Membrane in the Morphological Differentiation of Human Endothelial Cells into Capillary-like Structures. J. Cel Biol 107 (4), 1589-1598. doi:10.1083/jcb.107.4.1589

Kuczynski, E. A., and Reynolds, A. R. (2020). Vessel Co-option and Resistance to Anti-angiogenic Therapy. Angiogenesis 23 (1), 55-74. doi:10.1007/s10456-01909698-6

Lakka, S. S., Gondi, C. S., and Rao, J. S. (2005). Proteases and Glioma Angiogenesis. Brain Pathol. 15 (4), 327-341. doi:10.1111/j.1750-3639.2005.tb00118.x

Lathia, J. D., Li, M., Hall, P. E., Gallagher, J., Hale, J. S., Wu, Q., et al. (2012). Laminin Alpha 2 Enables Glioblastoma Stem Cell Growth. Ann. Neurol. 72 (5), 766-778. doi:10.1002/ana.23674

Ledur, P. F., Onzi, G. R., Zong, H., and Lenz, G. (2017). Culture Conditions Defining Glioblastoma Cells Behavior: what Is the Impact for Novel Discoveries. Oncotarget 8 (40), 69185-69197. doi:10.18632/oncotarget.20193

Leenders, W. P. J., Küsters, B., Verrijp, K., Maass, C., Wesseling, P., Heerschap, A., et al. (2004). Antiangiogenic Therapy of Cerebral Melanoma Metastases Results in Sustained Tumor Progression via Vessel Co-option. Clin. Cancer Res. 10 (18 Pt 1), 6222-6230. doi:10.1158/1078-0432.Ccr-04-0823

Li, Z., Bao, S., Wu, Q., Wang, H., Eyler, C., Sathornsumetee, S., et al. (2009). Hypoxia-inducible Factors Regulate Tumorigenic Capacity of Glioma Stem Cells. Cancer Cell 15 (6), 501-513. doi:10.1016/j.ccr.2009.03.018

Lin, R.-Z., and Chang, H.-Y. (2008). Recent Advances in Three-Dimensional Multicellular Spheroid Culture for Biomedical Research. Biotechnol. J. 3 (9-10), 1172-1184. doi:10.1002/biot.200700228

Liu, G., Yuan, X., Zeng, Z., Tunici, P., Ng, H., Abdulkadir, I. R., et al. (2006). Analysis of Gene Expression and Chemoresistance of CD133+ Cancer Stem Cells in Glioblastoma. Mol. Cancer 5, 67. doi:10.1186/1476-4598-5-67 
Louis, D. N., Perry, A., Wesseling, P., Brat, D. J., Cree, I. A., Figarella-Branger, D., et al. (2021). The 2021 WHO Classification of Tumors of the Central Nervous System: a Summary. Neuro Oncol. 23 (8), 1231-1251. doi:10.1093/neuonc/noab106

Lu, H., and Stenzel, M. H. (2018). Multicellular Tumor Spheroids (MCTS) as a 3D In Vitro Evaluation Tool of Nanoparticles. Small 14 (13), 1702858. doi:10.1002/ smll.201702858

Lyden, D., Hattori, K., Dias, S., Costa, C., Blaikie, P., Butros, L., et al. (2001). Impaired Recruitment of Bone-Marrow-Derived Endothelial and Hematopoietic Precursor Cells Blocks Tumor Angiogenesis and Growth. Nat. Med. 7 (11), 1194-1201. doi:10.1038/nm1101-1194

Mammoto, T., Jiang, A., Jiang, E., Panigrahy, D., Kieran, M. W., and Mammoto, A. (2013). Role of Collagen Matrix in Tumor Angiogenesis and Glioblastoma Multiforme Progression. Am. J. Pathol. 183 (4), 1293-1305. doi:10.1016/j. ajpath.2013.06.026

Mantovani, A., Sozzani, S., Locati, M., Allavena, P., and Sica, A. (2002). Macrophage Polarization: Tumor-Associated Macrophages as a Paradigm for Polarized M2 Mononuclear Phagocytes. Trends Immunol. 23 (11), 549-555. doi:10.1016/s1471-4906(02)02302-5

Marino, A., Camponovo, A., Degl'Innocenti, A., Bartolucci, M., Tapeinos, C., Martinelli, C., et al. (2019). Multifunctional Temozolomide-Loaded Lipid Superparamagnetic Nanovectors: Dual Targeting and Disintegration of Glioblastoma Spheroids by Synergic Chemotherapy and Hyperthermia Treatment. Nanoscale 11 (44), 21227-21248. doi:10.1039/c9nr07976a

Mazor, G., Levin, L., Picard, D., Ahmadov, U., Carén, H., Borkhardt, A., et al. (2019). The lncRNA TP73-AS1 Is Linked to Aggressiveness in Glioblastoma and Promotes Temozolomide Resistance in Glioblastoma Cancer Stem Cells. Cel Death Dis 10 (3), 246. doi:10.1038/s41419-019-1477-5

McCoy, M. G., Nyanyo, D., Hung, C. K., Goerger, J. P., R. Zipfel, R. M., Nishimura, N., et al. (2019). Endothelial Cells Promote 3D Invasion of GBM by IL-8dependent Induction of Cancer Stem Cell Properties. Sci. Rep. 9 (1), 9069. doi:10.1038/s41598-019-45535-y

Mendes, B., Marques, C., Carvalho, I., Costa, P., Martins, S., Ferreira, D., et al. (2015). Influence of Glioma Cells on a New Co-culture In Vitro Blood-Brain Barrier Model for Characterization and Validation of Permeability. Int. J. Pharmaceutics 490 (1-2), 94-101. doi:10.1016/j.ijpharm.2015.05.027

Méndez, O., Zavadil, J., Esencay, M., Lukyanov, Y., Santovasi, D., Wang, S.-C., et al. (2010). Knock Down of HIF-1a in Glioma Cells Reduces Migration In Vitro and Invasion In Vivo and Impairs Their Ability to Form Tumor Spheres. Mol. Cancer 9, 133. doi:10.1186/1476-4598-9-133

Miroshnikova, Y. A., Mouw, J. K., Barnes, J. M., Pickup, M. W., Lakins, J. N., Kim, Y., et al. (2016). Tissue Mechanics Promote IDH1-dependent HIFla-Tenascin C Feedback to Regulate Glioblastoma Aggression. Nat. Cel Biol 18 (12), 1336-1345. doi:10.1038/ncb3429

Miyai, M., Tomita, H., Soeda, A., Yano, H., Iwama, T., and Hara, A. (2017). Current Trends in Mouse Models of Glioblastoma. J. Neurooncol. 135 (3), 423-432. doi:10.1007/s11060-017-2626-2

Montana, V., and Sontheimer, H. (2011). Bradykinin Promotes the Chemotactic Invasion of Primary Brain Tumors. J. Neurosci. 31 (13), 4858-4867. doi:10. 1523/jneurosci.3825-10.2011

Mouw, J. K., Ou, G., and Weaver, V. M. (2014). Extracellular Matrix Assembly: a Multiscale Deconstruction. Nat. Rev. Mol. Cel Biol 15 (12), 771-785. doi:10. $1038 / \mathrm{nrm} 3902$

Novak, U., and Kaye, A. H. (2000). Extracellular Matrix and the Brain: Components and Function. J. Clin. Neurosci. 7 (4), 280-290. doi:10.1054/ jocn.1999.0212

Orr, B. A., and Eberhart, C. G. (2015). Molecular Pathways: Not a Simple Tube-The Many Functions of Blood Vessels. Clin. Cancer Res. 21 (1), 18-23. doi:10.1158/ 1078-0432.Ccr-13-1641

Ozturk, M. S., Lee, V. K., Zou, H., Friedel, R. H., Intes, X., and Dai, G. (2020). Highresolution Tomographic Analysis of In Vitro 3D Glioblastoma Tumor Model under Long-Term Drug Treatment. Sci. Adv. 6 (10), eaay7513. doi:10.1126/ sciadv.aay7513

Palamà, I. E., D'Amone, S., and Cortese, B. (2018). Microenvironmental Rigidity of 3D Scaffolds and Influence on Glioblastoma Cells: A Biomaterial Design Perspective. Front. Bioeng. Biotechnol. 6, 131. doi:10.3389/fbioe.2018.00131

Pan, C., Onda, K., and Hirano, T. (2019). Bevacizumab versus Anti-preeclamptic Drugs: Evaluation with Three-Dimensionally Co-cultured Human Mini Tumors. Anticancer Res. 39 (7), 3543-3551. doi:10.21873/anticanres.13500
Piao, Y.-J., Lee, C.-H., Zhu, M. J., Kye, K.-C., Kim, J.-M., Seo, Y.-J., et al. (2005). Involvement of Urokinase-type Plasminogen Activator in Sphingosylphosphorylcholine-Induced Angiogenesis. Exp. Dermatol. 14 (5), 356-362. doi:10.1111/j.0906-6705.2005.00272.x

Pyonteck, S. M., Akkari, L., Schuhmacher, A. J., Bowman, R. L., Sevenich, L., Quail, D. F., et al. (2013). CSF-1R Inhibition Alters Macrophage Polarization and Blocks Glioma Progression. Nat. Med. 19 (10), 1264-1272. doi:10.1038/nm. 3337

Qiang, L., Wu, T., Zhang, H.-W., Lu, N., Hu, R., Wang, Y.-J., et al. (2012). HIF-1 $\alpha$ Is Critical for Hypoxia-Mediated Maintenance of Glioblastoma Stem Cells by Activating Notch Signaling Pathway. Cell Death Differ 19 (2), 284-294. doi:10. 1038/cdd.2011.95

Rangarajan, A., and Weinberg, R. A. (2003). Comparative Biology of Mouse versus Human Cells: Modelling Human Cancer in Mice. Nat. Rev. Cancer 3 (12), 952-959. doi:10.1038/nrc1235

Reduce Refine Replace (2010). Reduce, Refine, Replace. Nat. Immunol. 11 (11), 971. doi:10.1038/ni1110-971

Riabov, V., Gudima, A., Wang, N., Mickley, A., Orekhov, A., and Kzhyshkowska, J. (2014). Role of Tumor Associated Macrophages in Tumor Angiogenesis and Lymphangiogenesis. Front. Physiol. 5, 75. doi:10.3389/fphys.2014.00075

Ruiz-Garcia, H., Alvarado-Estrada, K., Schiapparelli, P., Quinones-Hinojosa, A., and Trifiletti, D. M. (2020). Engineering Three-Dimensional Tumor Models to Study Glioma Cancer Stem Cells and Tumor Microenvironment. Front. Cel. Neurosci. 14, 558381. doi:10.3389/fncel.2020.558381

Rustad, K. C., Wong, V. W., Sorkin, M., Glotzbach, J. P., Major, M. R., Rajadas, J., et al. (2012). Enhancement of Mesenchymal Stem Cell Angiogenic Capacity and Stemness by a Biomimetic Hydrogel Scaffold. Biomaterials 33 (1), 80-90. doi:10.1016/j.biomaterials.2011.09.041

Rustamzadeh, E., Li, C., Doumbia, S., Hall, W. A., and Vallera, D. A. (2003). Targeting the Over-expressed Urokinase-type Plasminogen Activator Receptor on Glioblastoma Multiforme. J. Neurooncol. 65 (1), 63-75. doi:10.1023/a: 1026238331739

Scully, S., Francescone, R., Faibish, M., Bentley, B., Taylor, S. L., Oh, D., et al. (2012). Transdifferentiation of Glioblastoma Stem-like Cells into Mural Cells Drives Vasculogenic Mimicry in Glioblastomas. J. Neurosci. 32 (37), 12950-12960. doi:10.1523/jneurosci.2017-12.2012

Seano, G., and Jain, R. K. (2020). Vessel Co-option in Glioblastoma: Emerging Insights and Opportunities. Angiogenesis 23 (1), 9-16. doi:10.1007/s10456-01909691-z

Shabihkhani, M., Telesca, D., Movassaghi, M., Naeini, Y. B., Naeini, K. M., Hojat, S. A., et al. (2017). Incidence, Survival, Pathology, and Genetics of Adult Latino Americans with Glioblastoma. J. Neurooncol. 132 (2), 351-358. doi:10.1007/ s11060-017-2377-0

Shang, B., Liu, Y., Jiang, S.-j., and Liu, Y. (2015). Prognostic Value of TumorInfiltrating FoxP3+ Regulatory T Cells in Cancers: a Systematic Review and Meta-Analysis. Sci. Rep. 5, 15179. doi:10.1038/srep15179

Sherman, H., and Rossi, A. E. (2019). A Novel Three-Dimensional Glioma BloodBrain Barrier Model for High-Throughput Testing of Tumoricidal Capability. Front. Oncol. 9, 351. doi:10.3389/fonc.2019.00351

Sherwood, L. M., Parris, E. E., and Folkman, J. (1971). Tumor Angiogenesis: Therapeutic Implications. N. Engl. J. Med. 285 (21), 1182-1186. doi:10.1056/ nejm197111182852108

Shi, Y., Guryanova, O. A., Zhou, W., Liu, C., Huang, Z., Fang, X., et al. (2018). Ibrutinib Inactivates BMX-STAT3 in Glioma Stem Cells to Impair Malignant Growth and Radioresistance. Sci. Transl. Med. 10 (443). doi:10.1126/ scitranslmed.aah6816

Sielska, M., Przanowski, P., Wylot, B., Gabrusiewicz, K., Maleszewska, M., Kijewska, M., et al. (2013). Distinct Roles of CSF Family Cytokines in Macrophage Infiltration and Activation in Glioma Progression and Injury Response. J. Pathol. 230 (3), 310-321. doi:10.1002/path.4192

Soda, Y., Marumoto, T., Friedmann-Morvinski, D., Soda, M., Liu, F., Michiue, H., et al. (2011). Transdifferentiation of Glioblastoma Cells into Vascular Endothelial Cells. Proc. Natl. Acad. Sci. 108 (11), 4274-4280. doi:10.1073/ pnas. 1016030108

Sottoriva, A., Spiteri, I., Piccirillo, S. G. M., Touloumis, A., Collins, V. P., Marioni, J. C., et al. (2013). Intratumor Heterogeneity in Human Glioblastoma Reflects Cancer Evolutionary Dynamics. Proc. Natl. Acad. Sci. 110 (10), 4009-4014. doi:10.1073/pnas.1219747110 
Soubéran, A., and Tchoghandjian, A. (2020). Practical Review on Preclinical Human 3D Glioblastoma Models: Advances and Challenges for Clinical Translation. Cancers 12 (9), 2347. doi:10.3390/cancers12092347

Takenaka, M. C., Gabriely, G., Rothhammer, V., Mascanfroni, I. D., Wheeler, M. A., Chao, C.-C., et al. (2019). Control of Tumor-Associated Macrophages and T Cells in Glioblastoma via AHR and CD39. Nat. Neurosci. 22 (5), 729-740. doi:10.1038/s41593-019-0370-y

Tamura, R., Tanaka, T., Akasaki, Y., Murayama, Y., Yoshida, K., and Sasaki, H. (2019). The Role of Vascular Endothelial Growth Factor in the Hypoxic and Immunosuppressive Tumor Microenvironment: Perspectives for Therapeutic Implications. Med. Oncol. 37 (1), 2. doi:10.1007/s12032-019-1329-2

Tan, A. C., Ashley, D. M., López, G. Y., Malinzak, M., Friedman, H. S., and Khasraw, M. (2020). Management of Glioblastoma: State of the Art and Future Directions. CA A. Cancer J. Clin. 70 (4), 299-312. doi:10.3322/caac. 21613

Tang, M., Tiwari, S. K., Agrawal, K., Tan, M., Dang, J., Tam, T., et al. (2021). Rapid 3D Bioprinting of Glioblastoma Model Mimicking Native Biophysical Heterogeneity. Small 17 (15), 2006050. doi:10.1002/smll.202006050

Tatla, A. S., Justin, A. W., Watts, C., and Markaki, A. E. (2021a). A Vascularized Tumoroid Model for Human Glioblastoma Angiogenesis. bioRxiv 2002, 429930. doi:10.1101/2021.02.05.429930

Tatla, A. S., Justin, A. W., Watts, C., and Markaki, A. E. (2021b). A Vascularized Tumoroid Model for Human Glioblastoma Angiogenesis. Sci. Rep. 11 (1), 19550. doi:10.1038/s41598-021-98911-y

Truong, D., Fiorelli, R., Barrientos, E. S., Melendez, E. L., Sanai, N., Mehta, S., et al. (2019). A Three-Dimensional (3D) Organotypic Microfluidic Model for Glioma Stem Cells - Vascular Interactions. Biomaterials 198, 63-77. doi:10. 1016/j.biomaterials.2018.07.048

Vasudevan, J., Lim, C. T., and Fernandez, J. G. (2020). Cell Migration and Breast Cancer Metastasis in Biomimetic Extracellular Matrices with Independently Tunable Stiffness. Adv. Funct. Mater. 30 (49), 2005383. doi:10.1002/adfm. 202005383

Vega, E. A., Graner, M. W., and Sampson, J. H. (2008). Combating Immunosuppression in Glioma. Future Oncol. 4 (3), 433-442. doi:10.2217/ 14796694.4.3.433

Wang, D., Anderson, J. C., and Gladson, C. L. (2005). The Role of the Extracellular Matrix in Angiogenesis in Malignant Glioma Tumors. Brain Pathol. 15 (4), 318-326. doi:10.1111/j.1750-3639.2005.tb00117.x

Wang, H., Zhou, H., Xu, J., Lu, Y., Ji, X., Yao, Y., et al. (2021). Different T-Cell Subsets in Glioblastoma Multiforme and Targeted Immunotherapy. Cancer Lett. 496, 134-143. doi:10.1016/j.canlet.2020.09.028

Wang, Q., He, Z., Huang, M., Liu, T., Wang, Y., Xu, H., et al. (2018). Vascular Niche IL-6 Induces Alternative Macrophage Activation in Glioblastoma through HIF2a. Nat. Commun. 9 (1), 559. doi:10.1038/s41467-018-03050-0

Wang, S.-C., Hong, J.-H., Hsueh, C., and Chiang, C.-S. (2012). Tumor-secreted SDF-1 Promotes Glioma Invasiveness and TAM Tropism toward Hypoxia in a Murine Astrocytoma Model. Lab. Invest. 92 (1), 151-162. doi:10.1038/ labinvest.2011.128

Xiao, W., Wang, S., Zhang, R., Sohrabi, A., Yu, Q., Liu, S., et al. (2020). Bioengineered Scaffolds for 3D Culture Demonstrate Extracellular Matrix-Mediated Mechanisms of Chemotherapy Resistance in Glioblastoma. Matrix Biol. 85-86, 128-146. doi:10.1016/j.matbio.2019.04.003

Yan, G. N., Yang, L., Lv, Y. F., Shi, Y., Shen, L. L., Yao, X. H., et al. (2014). Endothelial Cells Promote Stem-like Phenotype of Glioma Cells through Activating the Hedgehog Pathway. J. Pathol. 234 (1), 11-22. doi:10.1002/path.4349
Yang, G. H., Yeo, M., Koo, Y. W., and Kim, G. H. (2019). 4D Bioprinting: Technological Advances in Biofabrication. Macromol. Biosci. 19 (5), 1800441. doi:10.1002/mabi.201800441

Yi, H.-G., Jeong, Y. H., Kim, Y., Choi, Y.-J., Moon, H. E., Park, S. H., et al. (2019). A Bioprinted Human-Glioblastoma-On-A-Chip for the Identification of Patientspecific Responses to Chemoradiotherapy. Nat. Biomed. Eng. 3 (7), 509-519. doi:10.1038/s41551-019-0363-x

Yu, F., Hunziker, W., and Choudhury, D. (2019). Engineering Microfluidic Organoid-On-A-Chip Platforms. Micromachines 10 (3), 165. doi:10.3390/ mi10030165

Yue, W.-Y., and Chen, Z.-P. (2005). Does Vasculogenic Mimicry Exist in Astrocytoma. J. Histochem. Cytochem. 53 (8), 997-1002. doi:10.1369/jhc.4A6521.2005

Zeiner, P. S., Preusse, C., Golebiewska, A., Zinke, J., Iriondo, A., Muller, A., et al. (2019). Distribution and Prognostic Impact of Microglia/macrophage Subpopulations in Gliomas. Brain Pathol. 29 (4), 513-529. doi:10.1111/bpa. 12690

Zhang, S., Ma, X., Zhu, C., Liu, L., Wang, G., and Yuan, X. (2016). The Role of Myeloid-Derived Suppressor Cells in Patients with Solid Tumors: A MetaAnalysis. PLoS One 11 (10), e0164514. doi:10.1371/journal.pone.0164514

Zhang, Y., Wang, S., and Dudley, A. C. (2020). Models and Molecular Mechanisms of Blood Vessel Co-option by Cancer Cells. Angiogenesis 23 (1), 17-25. doi:10. 1007/s10456-019-09684-y

Zhao, C., Gomez, G. A., Zhao, Y., Yang, Y., Cao, D., Lu, J., et al. (2018). ETV2 Mediates Endothelial Transdifferentiation of Glioblastoma. Sig Transduct Target. Ther. 3, 4. doi:10.1038/s41392-018-0007-8

Zhu, C., Chrifi, I., Mustafa, D., van der Weiden, M., Leenen, P. J. M., Duncker, D. J., et al. (2017). CECR1-mediated Cross Talk between Macrophages and Vascular Mural Cells Promotes Neovascularization in Malignant Glioma. Oncogene 36 (38), 5356-5368. doi:10.1038/onc.2017.145

Zhu, T. S., Costello, M. A., Talsma, C. E., Flack, C. G., Crowley, J. G., Hamm, L. L., et al. (2011). Endothelial Cells Create a Stem Cell Niche in Glioblastoma by Providing NOTCH Ligands that Nurture Self-Renewal of Cancer Stem-like Cells. Cancer Res. 71 (18), 6061-6072. doi:10.1158/0008-5472.Can-10-4269

Zou, M., Duan, Y., Wang, P., Gao, R., Chen, X., Ou, Y., et al. (2016). DYT-40, a Novel Synthetic 2-Styryl-5-Nitroimidazole Derivative, Blocks Malignant Glioblastoma Growth and Invasion by Inhibiting AEG-1 and NF-Kb Signaling Pathways. Sci. Rep. 6, 27331. doi:10.1038/srep27331

Conflict of Interest: The authors declare that the research was conducted in the absence of any commercial or financial relationships that could be construed as a potential conflict of interest.

Publisher's Note: All claims expressed in this article are solely those of the authors and do not necessarily represent those of their affiliated organizations, or those of the publisher, the editors, and the reviewers. Any product that may be evaluated in this article, or claim that may be made by its manufacturer, is not guaranteed or endorsed by the publisher.

Copyright $\odot 2022$ Pacheco, Martins, Monteiro, Baltazar, Costa and Sarmento. This is an open-access article distributed under the terms of the Creative Commons Attribution License (CC BY). The use, distribution or reproduction in other forums is permitted, provided the original author(s) and the copyright owner(s) are credited and that the original publication in this journal is cited, in accordance with accepted academic practice. No use, distribution or reproduction is permitted which does not comply with these terms. 


\section{GLOSSARY}

2D two-dimensional

3D three-dimensional

AEG-1 astrocyte elevated gene 1

BBB blood-brain barrier

bFGF basic fibroblast growth factor

CSF-1 colony stimulating factor 1

CTGF connective tissue growth factor

DLL4 delta like canonical Notch ligand 4

EC - endothelial cell

ECM extracellular matrix

EGF epidermal growth factor

EGFR epidermal growth factor receptor

eNOS endotelial nitric oxid synthetase

ETA endothelin receptor A

ETB endothelin receptor B

ETV2 ETS variant 2

FGF fibroblast growth factor

FITC fluorescein isothiocyanate

GAM glioblastoma-associated macrophage

GBM glioblastoma

GSC glioblastoma stem cell

GDNF glial cell derived neurotrophic factor

HIF-1a hypoxia inducible factor 1 alpha

HIF-2 $\boldsymbol{\alpha}$ hypoxia inducible factor 2 alpha

HUVEC human umbilical vein endothelial cell
ICAM-1 intracellular adhesion molecule 1

IDH isocitrate dehydrogenase

IL-6 interleukin 6

IL-8 interleukin 8

INF- $\boldsymbol{\gamma}$ interferon gamma

JAG 1 jagged canonical Notch ligand 1

MDSC myeloid-derived suppressor cells

MMP matrix metalloproteinase

NO nitric oxide

NOS not otherwise specified

PDMS polydimethylsiloxane

PEG polyethyleneglycol

PS polystyrene

SDF-1 stromal derived factor 1

Shh sonic hedgehog

TDEC tumor-derived endothelial cell

TERT telomerase reverse transcriptase

TNFa tumor necrosis factor alpha

TME tumor microenvironment

TP thymidine phosphorylase

Treg regulatory $\mathrm{T}$ cells

uTP urokinase-type plasminogen

UTPA

urokinase- type plasminogen activator

VCAM - 1 vascular adhesion molecule 1

VEGF vascular endothelial growth factor

VEGF-R vascular endothelial growth factor receptor 